\title{
National Hospital Ambulatory Medical Care Survey: 2017 Emergency Department Summary Tables
}

The Ambulatory and Hospital Care Statistics Branch is pleased to release the most current nationally representative data on ambulatory care visits to hospital emergency departments (EDs) in the United States. Estimates are presented on selected hospital, patient, and visit characteristics using data collected in the 2017 National Hospital Ambulatory Medical Care Survey (NHAMCS). NHAMCS is an annual nationally representative sample survey of visits to hospitals.

The sampling frame for the 2017 NHAMCS was constructed from IMS Health's Healthcare Organization Services database, also known as HCOS. NHAMCS uses a multistage probability design with samples of primary sampling units (PSUs), hospitals within PSUs, and patient visits within emergency service areas (ESAs) of each selected hospital. A total of 479 hospitals were selected for the 2017 NHAMCS, of which 374 were in scope and had eligible EDs. Of these, 234 responded, yielding an unweighted ED response rate of $62.6 \%$. A total of 331 ESAs were identified from the EDs. Of these, 240 responded fully or adequately by providing forms for at least one-half of their expected visits based on the total number of visits during the reporting period. In all, 16,709 Patient Record forms (PRFs) were submitted electronically. The resulting unweighted ESA sample response rate was $72.5 \%$, and the overall unweighted two-stage sampling response rate was $45.4 \%$ (48.4\% weighted).

The 2017 NHAMCS was conducted from December 26, 2016, through December 24, 2017. The U.S. Census Bureau was the data collection agent. NHAMCS data were collected electronically using a computerized instrument developed by the Census Bureau. Census field representatives completed PRFs for a sample of about 100 ED visits during a randomly assigned 4-week reporting period. The PRF content is available from: https://www.cdc.gov/nchs/ahcd/ahcd_survey_instruments.htm\#nhamcs.

Data processing and medical coding were performed by RTI International, Research Triangle Park, North Carolina. As part of the quality assurance procedure, a 13\% quality control sample of ED survey records was independently keyed and coded. Coding error rates ranged from $0.1 \%$ to $0.9 \%$ for the ED sample. For further details, see the 2017 NHAMCS public-use data file documentation available from: https://ftp.cdc.gov/pub/Health_Statistics/NCHS/Dataset_Documentation/NHAMCS/doc17_ed-508.pdf.

Web table estimates are based on sample data weighted to produce annual national estimates and include standard errors. The sample weight that is computed for each sample visit takes all stages of survey design into account. The survey data are inflated or weighted to produce unbiased national annual estimates. The visit weight includes three basic components: inflation by reciprocals of selection probabilities, adjustment for nonresponse, and population ratio adjustments. Estimates of the sampling variability were calculated using the Taylor series method in SUDAAN, which takes into account the complex sample design of NHAMCS. Detailed information on the design, conduct, and estimation procedures of 2017 NHAMCS are discussed in the public-use data file documentation.

As in any survey, results are subject to sampling and nonsampling errors. Nonsampling errors include reporting and processing errors as well as biases due to nonresponse and incomplete response. In 2017, race data were missing for 18.5\% (unweighted) of ED records, and ethnicity data were missing for $20.9 \%$ (unweighted) of ED records. The National Center for Health Statistics uses model-based single imputation for NHAMCS race and ethnicity data. The race imputation, based on research by an internal work group, is restricted to three categories (white, black, and other) because of quality concerns with imputed estimates for race categories other than white and black. The imputation technique is described in more detail in the public-use data file documentation. 
NHAMCS-ED diagnosis data are coded according to the International Classification of Diseases, 10th Revision, Clinical Modification (ICD-10-CM). Five tables (Tables 1 1, 12, 16, 17, and 26) presenting estimates of primary diagnoses, injury diagnoses, and primary hospital discharge diagnoses utilize ICD-10-CM codes and differ from pre-2016 Web tables presenting diagnosis estimates using the International Classification of Diseases, Ninth Revision, Clinical Modification (ICD-9-CM) coding system. Due to substantial differences between the ICD-9-CM and ICD-10-CM coding systems, users should take caution when comparing diagnosis estimates.

Proportion estimates are not presented or are flagged based on the procedure specified in "National Center for Health Statistics Data Presentation Standards for Proportions," available from: https://www.cdc.gov/nchs/data/series/sr_02/sr02_175.pdf. For all estimates other than estimates of proportions in the tables: Visit estimates are not presented if they are based on fewer than 30 cases in the sample data, in which case only an asterisk $\left(^{*}\right)$ appears. Visit estimates based on 30 or more cases include an asterisk if the relative standard error of the estimate exceeds $30 \%$.

Suggested citation: Rui P, Kang K. National Hospital Ambulatory Medical Care Survey: 2017 emergency department summary tables. National Center for Health Statistics. Available from: https://www.cdc.gov/nchs/data/nhamcs/web_tables/2017_ed_web_tables-508.pdf. 
Table 1. Emergency department visits, by selected characteristics: United States, 2017

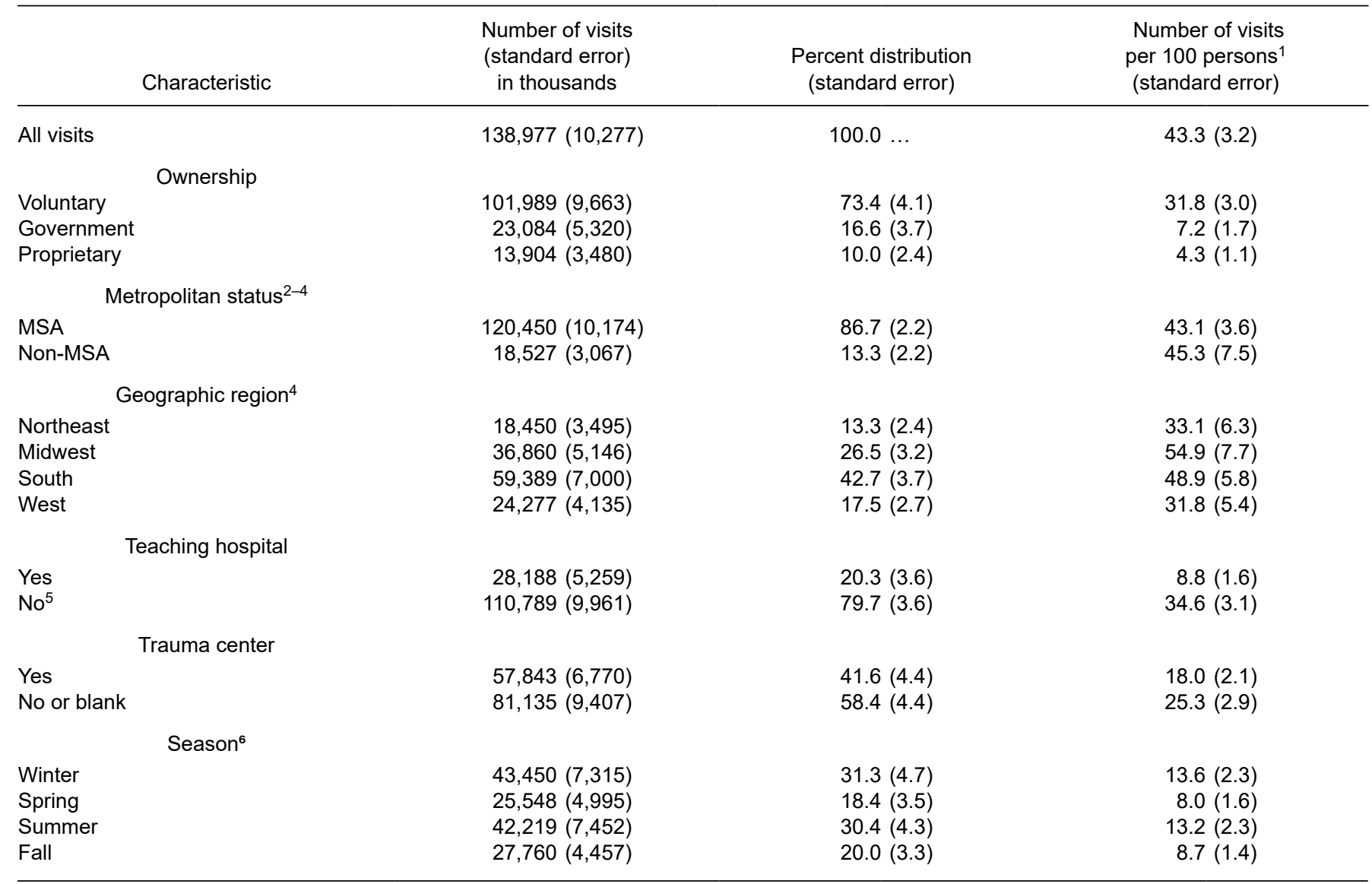

... Category not applicable.

${ }^{1}$ Visit rates for region are based on the July 1, 2017, set of estimates of the U.S. civilian noninstitutional population as developed by the U.S. Census Bureau, Population Division. ${ }^{2} \mathrm{MSA}$ is metropolitan statistical area.

${ }^{3}$ Population estimates by MSA are based on estimates of the U.S. civilian noninstitutionalized population as of July 1, 2017, from the 2017 National Health Interview Survey, compiled according to the 2013 Office of Management and Budget definitions of core-based statistical areas. More information about MSA definitions is available from: https://www.census.gov/

${ }^{4}$ rograms-surveys/metro-micro.html. ${ }^{5}$ Teaching status was unknown for $3.8 \%$ (weighted) of visits.

${ }^{6}$ Winter is December 22 to March 19, spring is March 20 to June 20, summer is June 21 to September 22, and fall is September 23 to December 21.

NOTE: Numbers may not add to totals because of rounding.

SOURCE: NCHS, National Hospital Ambulatory Medical Care Survey, 2017. 
Table 2. Emergency department visits, by patient age, sex, and residence: United States, 2017

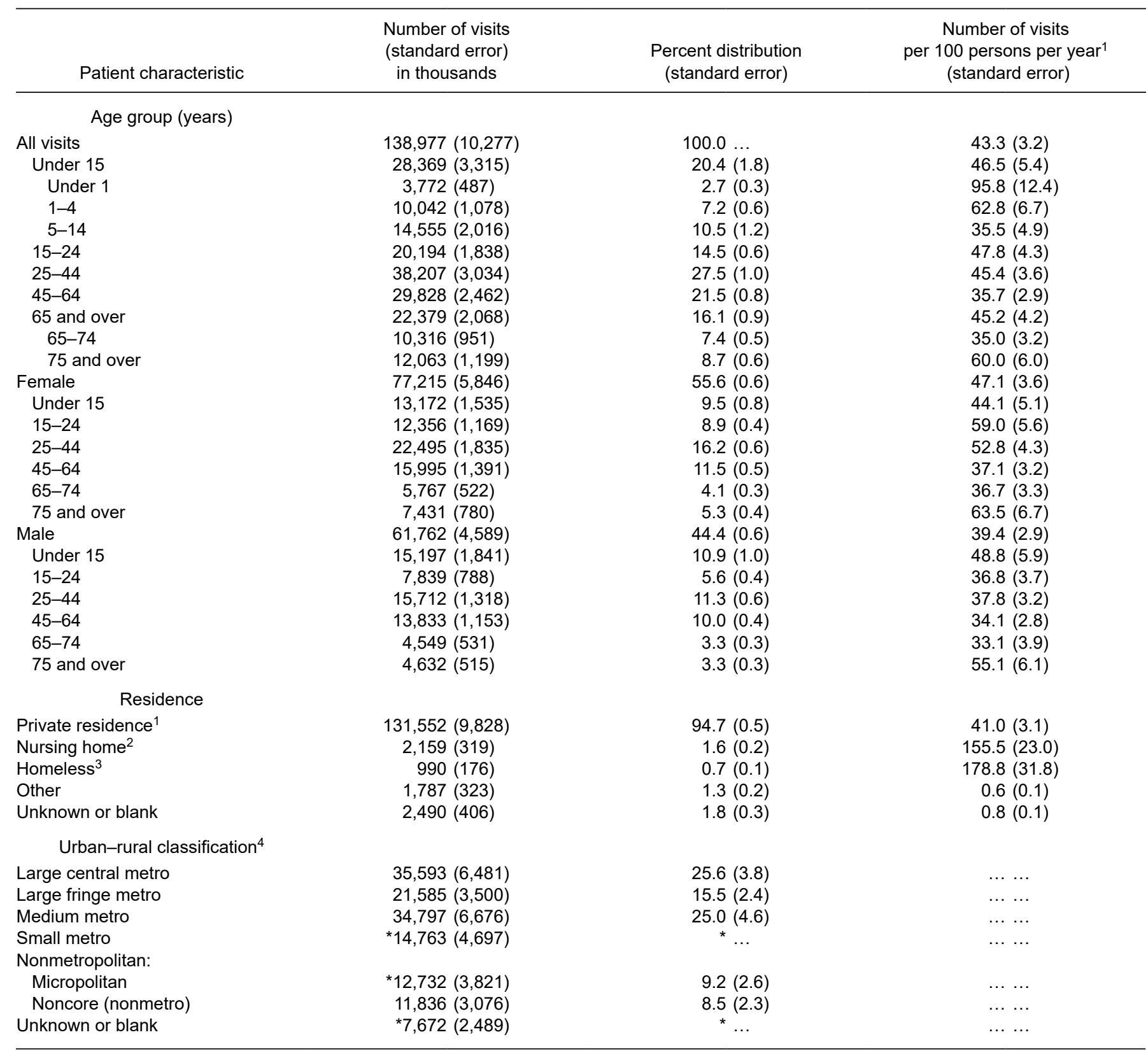

Category not applicable.

* Estimate does not meet NCHS standards of reliability.

${ }^{1}$ Visit rates for age, sex, and private residence are based on the July 1, 2017, set of estimates of the U.S. civilian noninstitutional population as developed by the U.S. Census Bureau, Population

Division.
${ }^{2}$ Visit rates for nursing home residents are based on the 2017 population denominators from the Centers for Medicare \& Medicaid Services, 2017 Minimum Data Set frequency reports, available from: https://www.cms.gov/Research-Statistics-Data-and-Systems/Computer-Data-and-Systems/Minimum-Data-Set-3-0-Public-Reports/Minimum-Data-Set-3-0-Frequency-Report.html.

${ }^{3}$ Visit rates for homeless people are based on the January 2017 estimate of people who were homeless on a given night, as reported in "The 2017 Annual Homeless Assessment Report (AHAR) to Congress," available from: https://files.hudexchange.info/resources/documents/2017-AHAR-Part-1.pdf.

${ }^{4}$ For each record, county of residence was determined using patient zip code and then matched to the National Center for Health Statistics Urban-Rural Classification Scheme for Counties, available from: https://www.cdc.gov/nchs/data access/urban rural.htm.

NOTES: Numbers may not add to totals because of rounding. Visit estimates are not presented if they are based on fewer than 30 cases in the sample data, in which case only an asterisk is shown. Visit estimates based on 30 cases or more include an asterisk if the relative standard error of the estimate exceeds $30 \%$. Proportion estimates are not presented if they are unreliable based on the procedure specified in "National Center for Health Statistics Data Presentation Standards for Proportions" (https://www.cdc.gov/nchs/data/series/sr_02/sr02_175.pdf), in which case only an asterisk is shown.

SOURCE: NCHS, National Hospital Ambulatory Medical Care Survey, 2017. 
Table 3. Emergency department visits, by patient race, age, and ethnicity: United States, 2017

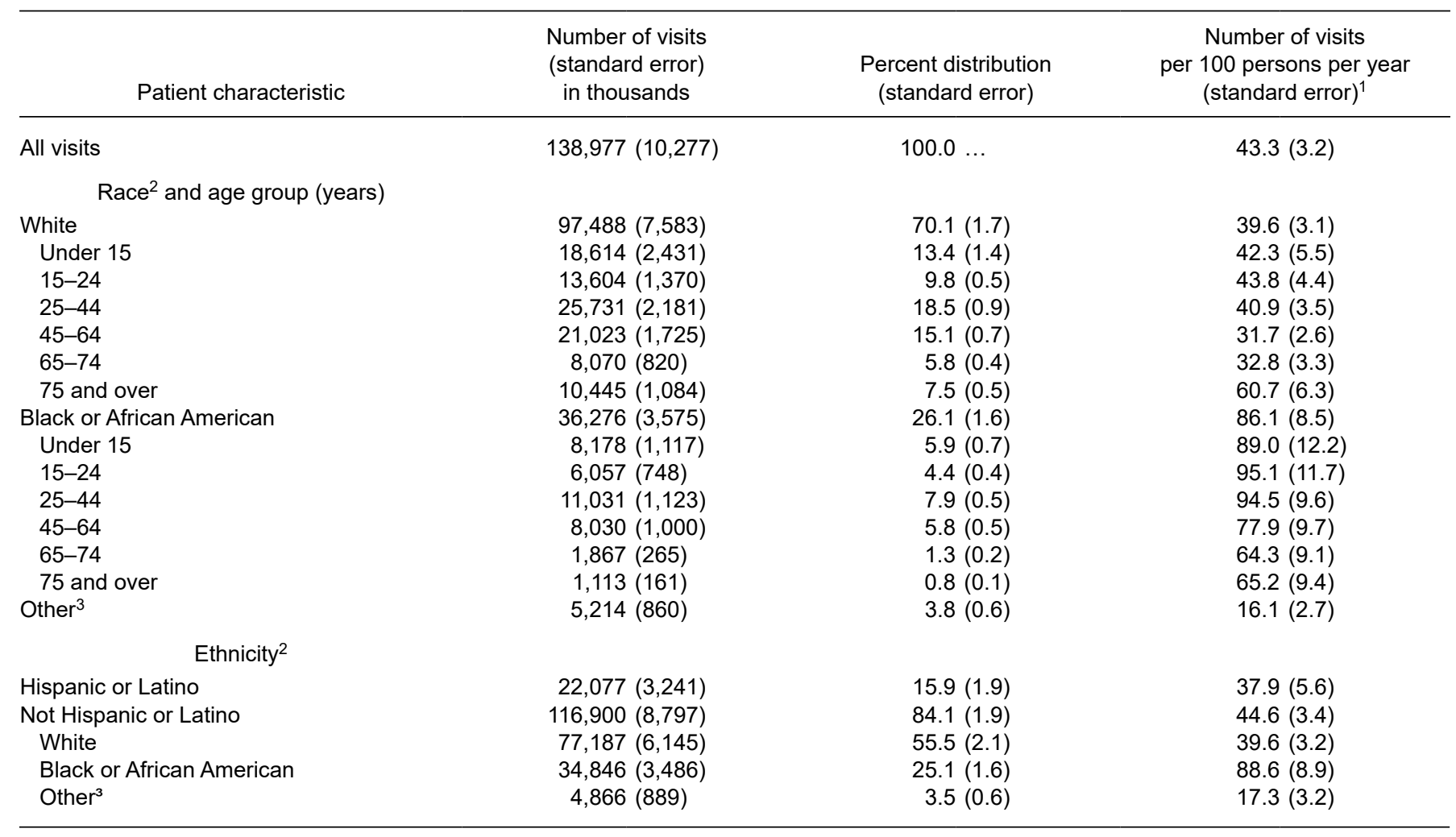

... Category not applicable.

Visit rates are based on the July 1, 2017, set of estimates of the U.S. civilian noninstitutionalized population as developed by the U.S. Census Bureau, Population Division.

2 The race groups white, black or African American, and other include persons of Hispanic and non-Hispanic origin. Persons of Hispanic origin may be of any race. For 2017, race data were missing for $15.0 \%$ (weighted) of visits, and ethnicity data were missing for $17.9 \%$ (weighted) of visits. Starting with 2009 data, the National Center for Health Statistics has adopted modelbased single imputation for National Hospital Ambulatory Medical Care Survey (NHAMCS) race and ethnicity data. The race imputation is restricted to three categories (white, black, and other) based on research by an internal work group and on quality concerns with imputed estimates for race categories other than white and black. The imputation technique is detailed in the 2009 NHAMCS public-use data file documentation, available from: https://ftp.cdc.gov/pub/Health_Statistics/NCHS/Dataset_Documentation/NHAMCS/doc09.pdf.

${ }^{3}$ Includes Asian, Native Hawaiian or Other Pacific Islander, American Indian or Alaska Native, and persons with more than one race.

NOTE: Numbers may not add to totals because of rounding.

SOURCE: NCHS, National Hospital Ambulatory Medical Care Survey, 2017. 
Table 4. Wait time at emergency department visits: United States, 2017

\begin{tabular}{|c|c|c|}
\hline Visit characteristic & $\begin{array}{l}\text { Number of visits } \\
\text { (standard error) } \\
\text { in thousands }\end{array}$ & $\begin{array}{l}\text { Percent distribution } \\
\text { (standard error) }\end{array}$ \\
\hline \multicolumn{3}{|c|}{ Time spent waiting to see a physician, APRN, or $\mathrm{PA}^{1}$} \\
\hline Fewer than 15 minutes & $56,081(5,879)$ & $40.4(2.9)$ \\
\hline 2 hours, but less than 3 hours & $3,845(492)$ & $2.8(0.3)$ \\
\hline 3 hours, but less than 4 hours & $1,319(192)$ & $0.9(0.1)$ \\
\hline 4 hours, but less than 6 hours & $1,222(220)$ & $0.9(0.2)$ \\
\hline 6 hours or more & 731 (190) & $0.5(0.1)$ \\
\hline Not applicable & $3,592(508)$ & $2.6(0.3)$ \\
\hline Blank & $14,029(2,532)$ & $10.1(1.8)$ \\
\hline Blank & *1,923 (661) & $1.4(0.5)$ \\
\hline
\end{tabular}

... Category not applicable.

*.. Estimate does not meet NCHS standards of reliability.

${ }^{1}$ APRN is advanced practice registered nurse. PA is physician assistant. The median wait time to see a physician, APRN, or PA was 16 minutes; the mean wait time to see a physician, APRN, or PA was 37.5 minutes.

${ }^{2}$ Business hours are defined as Monday through Friday, 8 a.m. to 5 p.m.

NOTES: Numbers may not add to totals because of rounding. Visit estimates based on 30 cases or more include an asterisk if the relative standard error of the estimate exceeds $30 \%$.

SOURCE: NCHS, National Hospital Ambulatory Medical Care Survey, 2017. 
Table 5. Mode of arrival at emergency department, by patient age: United States, 2017

\begin{tabular}{|c|c|c|c|c|c|}
\hline \multirow[b]{2}{*}{ Age group (years) } & \multirow{2}{*}{$\begin{array}{c}\text { Number of visits } \\
\text { in thousands }\end{array}$} & \multicolumn{4}{|c|}{ Patient's mode of arrival } \\
\hline & & Total $^{1}$ & Ambulance & Other & Unknown or blank \\
\hline & & & \multicolumn{3}{|c|}{ Percent distribution (standard error) } \\
\hline All visits & 138,977 & 100.0 & $14.5(0.8)$ & $82.7(1.2)$ & $2.8(0.7)$ \\
\hline Under 15 & 28,369 & 100.0 & $4.4(0.6)$ & **90.7 (2.9) & * $\ldots$ \\
\hline Under 1 & 3,772 & 100.0 & $3.6(0.9)$ & **88.0 (5.3) & * $\ldots$ \\
\hline $1-4$ & 10,042 & 100.0 & $4.1(0.8)$ & **92.0 (2.4) & * $\ldots$ \\
\hline $5-14$ & 14,555 & 100.0 & $4.9(1.0)$ & $90.5(2.7)$ & * $\ldots$ \\
\hline $15-24$ & 20,194 & 100.0 & $8.9(0.9)$ & $88.8(1.0)$ & $2.3(0.7)$ \\
\hline $25-44$ & 38,207 & 100.0 & $11.3(1.1)$ & $86.4(1.4)$ & $2.3(0.5)$ \\
\hline $45-64$ & 29,828 & 100.0 & $18.4(1.3)$ & $79.9(1.4)$ & $1.8(0.3)$ \\
\hline 65 and over & 22,379 & 100.0 & $32.6(1.7)$ & $64.6(1.7)$ & $2.8(0.6)$ \\
\hline $65-74$ & 10,316 & 100.0 & $24.4(2.0)$ & $72.4(2.2)$ & $3.2(0.8)$ \\
\hline 75 and over & 12,063 & 100.0 & $39.6(2.2)$ & $58.0(2.3)$ & $2.4(0.9)$ \\
\hline
\end{tabular}

** Estimate meets NCHS standards of reliability, but its complement does not.

* Estimate does not meet NCHS standards of reliability.

... Category not applicable.

${ }^{1}$ Ambulance was the mode of arrival for 20,123,000 visits; other was the mode of arrival for 115,967,000 visits.

NOTES: Numbers may not add to totals because of rounding. Visit estimates are not presented if they are based on fewer than 30 cases in the sample data, in which case only an asterisk is shown. Visit estimates based on 30 cases or more include an asterisk if the relative standard error of the estimate exceeds $30 \%$. Proportion estimates are not presented if they are unreliable based on the procedure specified in "National Center for Health Statistics Data Presentation Standards for Proportions" (https://www.cdc.gov/nchs/data/series/sr_02/sr02_175.pdf), in which case only an asterisk is shown.

SOURCE: NCHS, National Hospital Ambulatory Medical Care Survey, 2017. 
Table 6. Expected source of payment at emergency department visits: United States, 2017

\begin{tabular}{|c|c|c|}
\hline Payment source & $\begin{array}{c}\text { Number of visits }{ }^{1} \\
\text { (standard error) } \\
\text { in thousands }\end{array}$ & $\begin{array}{l}\text { Percent of visits } \\
\text { (standard error) }\end{array}$ \\
\hline All visits & $138,977(10,277)$ & $\ldots \ldots$ \\
\hline Private insurance & $43,352(3,660)$ & $31.2(1.5)$ \\
\hline Medicaid or $\mathrm{CHIP}^{2}$ or other state-based program & $55,957(5,693)$ & $40.3(2.4)$ \\
\hline Medicare & $25,663(2,361)$ & $18.5(1.1)$ \\
\hline Medicare and Medicaid ${ }^{3}$ & $5,040(737)$ & $3.6(0.5)$ \\
\hline No insurance ${ }^{4}$ & $11,119(1,632)$ & $8.0(1.0)$ \\
\hline Self-pay & $10,782(1,611)$ & $7.8(1.0)$ \\
\hline No change or charity & ${ }^{*} 671(245)$ & $0.5(0.2)$ \\
\hline Worker's compensation & $1,208(190)$ & $0.9(0.1)$ \\
\hline Other & $6,081(1,261)$ & $4.4(0.9)$ \\
\hline Unknown or blank & $13,655(3,210)$ & $9.8(2.3)$ \\
\hline
\end{tabular}

.. Category not applicable.

*Estimate does not meet NCHS standards of reliability.

${ }^{1}$ Total exceeds "All visits" and percentage exceeds $100 \%$ because more than one source of payment may be reported per visit.

${ }^{2}$ Children's Health Insurance Program.

${ }^{3}$ Visits are also included in the "Medicaid or CHIP or other state-based program" and "Medicare" categories.

${ }^{4}$ Defined as having only self-pay, no charge, or charity as payment sources.

NOTE: Numbers may not add to totals because of rounding.

SOURCE: NCHS, National Hospital Ambulatory Medical Care Survey, 2017. 
Table 7. Triage status of emergency department visits, by selected patient characteristics: United States, 2017

\begin{tabular}{|c|c|c|c|c|c|c|c|c|c|}
\hline $\begin{array}{l}\text { Patient and visit } \\
\text { characteristic }\end{array}$ & $\begin{array}{l}\text { Number of visits } \\
\text { in thousands }\end{array}$ & Total & $\begin{array}{c}\text { Level } 1 \\
\text { (immediate) }\end{array}$ & $\begin{array}{l}\text { Level } 2 \\
\text { (emergent) }\end{array}$ & $\begin{array}{l}\text { Level } 3 \\
\text { (urgent) }\end{array}$ & $\begin{array}{c}\text { Level } 4 \\
\text { (semiurgent) }\end{array}$ & $\begin{array}{c}\text { Level } 5 \\
\text { (nonurgent) }\end{array}$ & No triage $^{1}$ & $\begin{array}{l}\text { Unknown or } \\
\text { blank }\end{array}$ \\
\hline & & & \multicolumn{7}{|c|}{ Percent distribution (standard error) } \\
\hline All visits & 138,977 & 100.0 & $0.9(0.3)$ & $9.9(1.1)$ & $33.9(2.4)$ & $24.0(2.2)$ & $3.9(0.7)$ & ${ }^{*} \ldots$ & $22.3(3.9)$ \\
\hline \multicolumn{10}{|l|}{ Age group (years) } \\
\hline Under 15 & 28,369 & 100.0 & $0.7(0.6)$ & $6.2(1.4)$ & $26.1(2.5)$ & $34.9(3.0)$ & $7.8(2.0)$ & * & $19.1(3.8)$ \\
\hline Under 1 & 3,772 & 100.0 & * $\ldots$ & $10.2(2.6)$ & $21.5(2.4)$ & $36.8(3.6)$ & $8.8(1.6)$ & ${ }^{*} \ldots$ & $17.1(3.3)$ \\
\hline $1-4$ & 10,042 & 100.0 & $0.8(0.6)$ & $4.6(0.9)$ & $22.1(2.5)$ & $34.0(3.0)$ & $9.7(2.7)$ & ${ }^{*} \ldots$ & $23.3(4.5)$ \\
\hline $5-14$ & 14,555 & 100.0 & $0.7(0.6)$ & $6.3(1.8)$ & $30.0(3.3)$ & $35.1(3.4)$ & *. & ${ }^{*} \ldots$ & $16.8(3.7)$ \\
\hline $15-24$ & 20,194 & 100.0 & $1.2(0.5)$ & $9.0(1.7)$ & $32.4(2.5)$ & $24.9(2.9)$ & $4.1(0.7)$ & * ... & $23.7(4.4)$ \\
\hline $25-44$ & 38,207 & 100.0 & $0.7(0.3)$ & $7.0(0.9)$ & $34.1(2.8)$ & $25.3(2.4)$ & $3.1(0.6)$ & * $\ldots$ & $24.2(4.5)$ \\
\hline $45-64$ & 29,828 & 100.0 & $0.9(0.3)$ & $12.1(1.5)$ & $37.2(3.0)$ & $18.4(1.8)$ & $2.7(0.6)$ & ${ }^{*} \ldots$ & $23.5(4.7)$ \\
\hline 65 and over & 22,379 & 100.0 & $1.0(0.2)$ & $17.4(2.3)$ & $40.4(3.4)$ & $14.6(2.4)$ & $1.6(0.4)$ & ${ }^{*} \ldots$ & $20.0(3.7)$ \\
\hline $65-74$ & 10,316 & 100.0 & $1.1(0.3)$ & $17.1(2.8)$ & $38.2(3.3)$ & $15.8(2.2)$ & $2.0(0.6)$ & * $\ldots$ & $22.0(4.0)$ \\
\hline 75 and over & 12,063 & 100.0 & $0.8(0.3)$ & $17.6(2.3)$ & $42.3(3.9)$ & $13.5(3.0)$ & $1.3(0.4)$ & * $\ldots$ & $18.3(3.7)$ \\
\hline \multicolumn{10}{|l|}{ Sex } \\
\hline Female & 77,215 & 100.0 & $0.7(0.3)$ & $9.4(1.1)$ & $36.3(2.7)$ & $22.5(2.1)$ & $3.6(0.7)$ & * $\ldots$ & $22.4(4.1)$ \\
\hline Male & 61,762 & 100.0 & $1.1(0.4)$ & $10.6(1.2)$ & $30.9(2.0)$ & $25.8(2.4)$ & $4.3(0.7)$ & * $\ldots$ & $22.1(3.7)$ \\
\hline \multicolumn{10}{|l|}{ Race $^{2}$} \\
\hline White & 97,488 & 100.0 & $0.6(0.1)$ & $10.2(1.0)$ & $35.1(2.4)$ & $23.9(2.3)$ & $4.1(0.9)$ & * $\ldots$ & $20.3(3.5)$ \\
\hline Black or African American & 36,276 & 100.0 & * $\ldots$ & $9.1(2.0)$ & $31.8(3.2)$ & $23.7(2.8)$ & $3.5(0.5)$ & ${ }^{*} \ldots$ & $27.3(6.4)$ \\
\hline Other $^{3}$ & 5,214 & 100.0 & * $\ldots$ & $9.2(2.4)$ & $26.8(4.9)$ & ${ }^{*} \ldots$ & $2.0(1.0)$ & * $\ldots$ & $24.5(7.0)$ \\
\hline \multicolumn{10}{|l|}{ Ethnicity and race ${ }^{2}$} \\
\hline Hispanic or Latino & 22,077 & 100.0 & $0.9(0.4)$ & $8.8(1.4)$ & $32.0(3.6)$ & $26.3(3.0)$ & ${ }^{*} \ldots$ & ${ }^{*} \ldots$ & $16.2(3.7)$ \\
\hline Not Hispanic or Latino & 116,900 & 100.0 & $0.9(0.4)$ & $10.1(1.2)$ & $34.3(2.5)$ & $23.6(2.4)$ & $3.5(0.5)$ & $4.3(1.3)$ & $23.4(4.3)$ \\
\hline White & 77,187 & 100.0 & $0.6(0.1)$ & $10.7(1.1)$ & $36.0(2.6)$ & $23.3(2.6)$ & $3.6(0.7)$ & *... & $21.3(4.0)$ \\
\hline Black or African American & 34,846 & 100.0 & * $\ldots$ & $9.0(1.9)$ & $31.4(3.2)$ & $23.6(2.9)$ & $3.4(0.5)$ & * $\ldots$ & $27.9(6.5)$ \\
\hline Other ${ }^{3}$ & 4,866 & 100.0 & * $\ldots$ & $9.1(2.6)$ & $27.0(5.4)$ & * $\ldots$ & * $\ldots$ & * $\ldots$ & * $\ldots$ \\
\hline
\end{tabular}


Table 7. Triage status of emergency department visits, by selected patient characteristics: United States, 2017-Con.

Patient and visit

Number of visits

in thousands

Total

Level 1

Level 2

Level 3

Level

urgent)

(semiurgent)

Level 5

(nonurgent)

No triage $^{1}$

Unknown or

blank

Expected source of payment ${ }^{4}$

Private insurance

Medicaid or $\mathrm{CHIP}^{5}$ or other

state-based program

43,352

100.0

Percent distribution (standard error)

edicare

Medicare and Medicaid ${ }^{6}$

No insurance ${ }^{7}$

Worker's compensation

55,957

25,663

5,040

Other

11,119

1,208

Unknown or blank

13,655

$\begin{array}{cc}100.0 & 0.6(0.2) \\ 100.0 & 0.8(0.2) \\ 100.0 & 1.1(0.4) \\ 100.0 & \text { * } \ldots \\ 100.0 & \text { * } \ldots \\ 100.0 & \text { * } \ldots \\ 100.0 & 0.9(0.4)\end{array}$

$12.1(1.6)$

$37.7(2.9)$

$23.0(3.0)$

$3.6(0.8)$

* $\ldots$

$16.4(2.9)$

... Category not applicable.

Estims

(

${ }^{2}$ The race groups white, black or African American, and other include persons of Hispanic and non-Hispanic origin. Persons of Hispanic origin may be of any race. For 2017 , race data were missing for $15.0 \%$ (weighted) of visits, and ethnicity data were missing for 17.9\% (weighted) of visits. Starting with 2009 data, the National Center for Health Statistics has adopted model-based single imputation for National Hospital Ambulatory Medical Care Survey (NHAMCS) race and ethnicity data. The race imputation is restricted to three categories (white, black, and other) based on research by an internal work group and on quality concerns with imputed estimates for race categories other than white and black. The imputation technique is detailed in the 2009 NHAMCS public-use data file documentation, available from: https://ftp.cdc.gov/pub/Health_Statistics/NCHS/Dataset_Documentation/NHAMCS/doc09.pd.

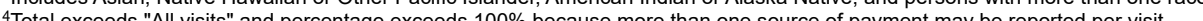

${ }^{5}$ Children's Health Insurance Progntage

"Visits are also included in both the "Medicaid or CHIP or other state-based program" and "Medicare" categories.

'Defined as having only self-pay, no charge, or charity as payment sources.

NOTES: The 2017 Patient Record Form (PRF) requested responses using a 1-5 scale. PRF responses were evaluated with reference to responses on the Ambulatory Unit Record (completed during induction) to the question, "How many levels are in

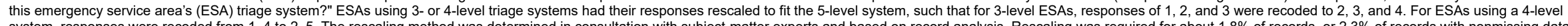

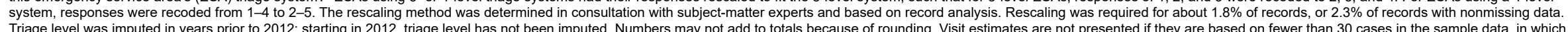

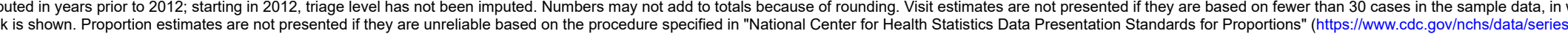
Sr_02/sr02_175.pdf), in which case only an asterisk is shown.

SOURCE: NCHS, National Hospital Ambulatory Medical Care Survey, 2017 
Table 8. Initial blood pressure measurements recorded at emergency department visits for adults, by selected patient characteristics: United States, 2017

Initial blood pressure

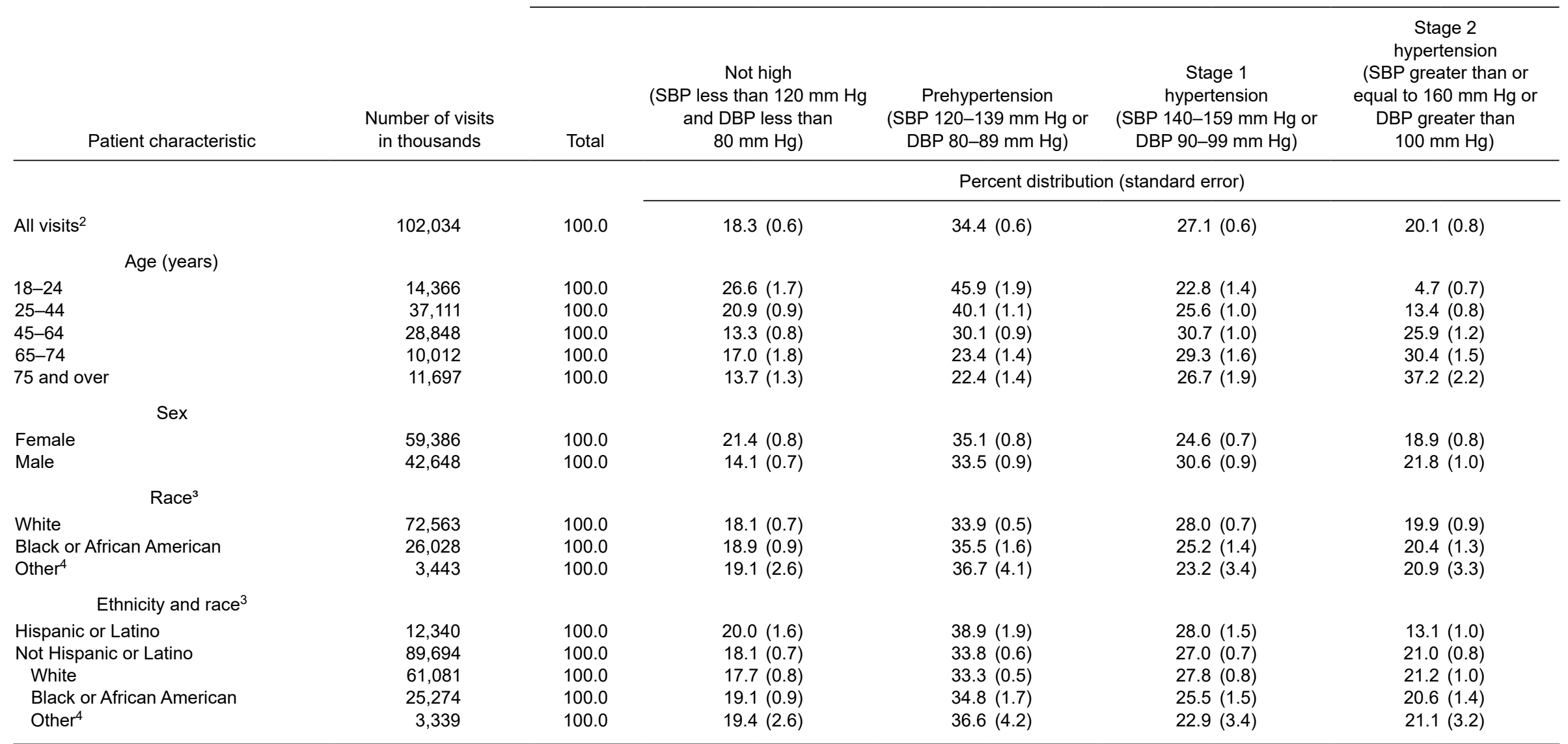

SBP is systolic blood pressure; DBP is diastolic blood pressure. Three high blood pressure categories (with SBP more than $120 \mathrm{~mm} \mathrm{Hg}$ or DBP more than $80 \mathrm{~mm} \mathrm{Hg}$ ) are based on "The Seventh Report of the Joint National Committee on Prevention, Detection, Evaluation, and Treatment of High Blood Pressure" and correspond to prehypertensive, stage 1 hypertensive, and stage 2 hypertensive ranges. If SBP and DBP fall into two categories, the visit is included in the higher blood pressure category.

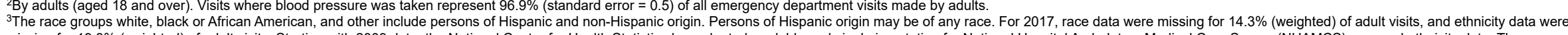
imputation is restricted to three categories (white, black, and other) based on research by an internal work group and on quality concerns with imputed estimates for roce cat Amburies other than white and black. The imputation technique is detailed in the 2009 NHAMCS public-use data file documentation, available from: https:/ftp. cdc gov/pub/Health Statistics/NCHS/Dataset Documentation/NHAMCS/doc09 pdf.

${ }^{4}$ Includes Asian, Native Hawaiian or Other Pacific Islander, American Indian or Alaska Native, and persons with more than one race.

NOTE: Numbers may not add to totals because of rounding.

SOURCE: NCHS, National Hospital Ambulatory Medical Care Survey, 2017 
Table 9. Initial temperature, pulse oximetry, and visit history at emergency department visits: United States, 2017

\begin{tabular}{|c|c|c|}
\hline Visit characteristic & $\begin{array}{l}\text { Number of visits } \\
\text { (standard error) } \\
\text { in thousands }\end{array}$ & $\begin{array}{l}\text { Percent distribution } \\
\text { (standard error) }\end{array}$ \\
\hline All visits & $138,977(10,277)$ & $100.0 \ldots$ \\
\hline \multicolumn{3}{|l|}{ Temperature } \\
\hline Febrile: higher than $38.0^{\circ} \mathrm{C}$ or higher than $100.4^{\circ} \mathrm{F}$ & $5,159(549)$ & $3.7(0.3)$ \\
\hline Normal: $35.1^{\circ} \mathrm{C}-38.0^{\circ} \mathrm{C}$ or $95.1^{\circ} \mathrm{F}-100.4^{\circ} \mathrm{F}$ & $126,418(9,632)$ & $91.0(0.7)$ \\
\hline Hypothermic: $35.0^{\circ} \mathrm{C}$ and below or $95.0^{\circ} \mathrm{F}$ and below & *... & $0.1(0.0)$ \\
\hline Blank & $7,302(855)$ & $5.3(0.6)$ \\
\hline \multicolumn{3}{|l|}{ Pulse oximetry ${ }^{1}$} \\
\hline $95 \%-100 \%$ & $119,505(8,908)$ & $86.0(1.4)$ \\
\hline Less than $95 \%$ & $9,798(1,053)$ & $7.1(0.6)$ \\
\hline Blank & $9,674(1,969)$ & $7.0(1.2)$ \\
\hline \multicolumn{3}{|l|}{ Episode of care } \\
\hline Initial visit & $125,242(9,679)$ & $90.1(1.1)$ \\
\hline Follow-up visit & 7,336 (900) & $5.3(0.5)$ \\
\hline Unknown or blank & $6,400(1,468)$ & $4.6(1.1)$ \\
\hline \multicolumn{3}{|l|}{$\begin{array}{l}\text { Patient seen in this emergency department } \\
\text { within the last } 72 \text { hours }\end{array}$} \\
\hline Yes & 4,339 (841) & $3.1(0.6)$ \\
\hline No & $125,496(10,487)$ & $90.3(1.7)$ \\
\hline Unknown or blank & $9,142(2,222)$ & $6.6(1.7)$ \\
\hline
\end{tabular}

... Category not applicable.

* Estimate does not meet NCHS standards of reliability.

0.0 Quantity more than zero but less than 0.05 .

${ }^{1}$ Normal oxygen saturation as measured by pulse oximetry is $95 \%$ or more.

NOTES: Numbers may not add to totals because of rounding. Visit estimates are not presented if they are based on fewer than 30 cases in the sample data, in which case only an asterisk is shown. Proportion estimates are not presented if they are unreliable based on the procedure specified in "National Center for Health Statistics Data Presentation Standards for Proportions" (https://www.cdc.gov/nchs/data/series/sr_02/sr02_175.pdf), in which case only an asterisk is shown.

SOURCE: NCHS, National Hospital Ambulatory Medical Care Survey, 2017. 
Table 10. Ten principal reasons for emergency department visits, by patient age and sex: United States, 2017

\begin{tabular}{|c|c|c|c|}
\hline Principal reason for visit and RVC code ${ }^{1}$ & & $\begin{array}{l}\text { Number of visits } \\
\text { (standard error) } \\
\text { in thousands }\end{array}$ & $\begin{array}{l}\text { Percent distribution } \\
\text { (standard error) }\end{array}$ \\
\hline All visits & $\ldots$ & $138,977(10,277)$ & $100.0 \ldots$ \\
\hline Stomach and abdominal pain, cramps and spasms & S545 & $12,248(1,132)$ & $8.8(0.4)$ \\
\hline Chest pain and related symptoms & S050 & $6,523(540)$ & $4.7(0.2)$ \\
\hline Fever & S010 & $5,491(631)$ & $4.0(0.4)$ \\
\hline Cough & S440 & $5,033(524)$ & $3.6(0.3)$ \\
\hline Shortness of breath & S415 & 3,988 (457) & $2.9(0.2)$ \\
\hline Pain, specified site not referable to a specific body system & S055 & $3,642(402)$ & $2.6(0.2)$ \\
\hline Headache, pain in head & S210 & $3,508(302)$ & $2.5(0.1)$ \\
\hline Back symptoms & S905 & $3,290(376)$ & $2.4(0.2)$ \\
\hline Vomiting & S530 & $2,964(357)$ & $2.1(0.2)$ \\
\hline Symptoms referable to throat & S455 & $2,787(305)$ & $2.0(0.2)$ \\
\hline All other reasons ${ }^{2}$ & $\ldots$ & $89,504(6,626)$ & $64.4(0.6)$ \\
\hline All visits under age 15 years & $\ldots$ & $28,369(3,315)$ & $100.0 \ldots$ \\
\hline Female & $\ldots$ & $13,172(1,535)$ & $46.4(1.1)$ \\
\hline Fever & S010 & $2,031(276)$ & $7.2(0.6)$ \\
\hline Cough & S440 & $987(174)$ & $3.5(0.6)$ \\
\hline Skin rash & S860 & $602(114)$ & $2.1(0.4)$ \\
\hline Stomach and abdominal pain, cramps and spasms & S545 & $593(153)$ & $2.1(0.4)$ \\
\hline Vomiting & S530 & $566(121)$ & $2.0(0.3)$ \\
\hline Symptoms referable to throat & S455 & $404(92)$ & $1.4(0.3)$ \\
\hline Headache, pain in head & S210 & $374(109)$ & $1.3(0.3)$ \\
\hline Earache or ear infection & S355 & $357(71)$ & $1.3(0.3)$ \\
\hline Injury, other and unspecified of head, neck, and face & J505 & $293(85)$ & $1.0(0.3)$ \\
\hline Diarrhea & S595 & * ... & $0.9(0.2)$ \\
\hline All other reasons ${ }^{2}$ & $\ldots$ & $6,704(852)$ & $23.6(0.8)$ \\
\hline Male & $\ldots$ & $15,197(1,841)$ & $53.6(1.1)$ \\
\hline Fever & S010 & $2,198(322)$ & $7.7(0.9)$ \\
\hline Cough & S440 & $1,219(165)$ & $4.3(0.4)$ \\
\hline Stomach and abdominal pain, cramps and spasms & S545 & $752(191)$ & $2.7(0.5)$ \\
\hline Vomiting & S530 & $721(119)$ & $2.5(0.3)$ \\
\hline Injury, other and unspecified of head, neck, and face & J505 & $688(184)$ & $2.4(0.6)$ \\
\hline Skin rash & S860 & $663(141)$ & $2.3(0.4)$ \\
\hline Earache or ear infection & S355 & $477(106)$ & $1.7(0.3)$ \\
\hline Symptoms referable to throat & S455 & $398(103)$ & $1.4(0.4)$ \\
\hline Nasal congestion & S400 & $283(54)$ & $1.0(0.2)$ \\
\hline Laceration or cut of facial area & $\mathrm{J} 210$ & * ... & $0.9(0.2)$ \\
\hline All other reasons ${ }^{2}$ & $\ldots$ & $7,538(1,025)$ & $26.6(1.3)$ \\
\hline
\end{tabular}


Table 10. Ten principal reasons for emergency department visits, by patient age and sex: United States, 2017-Con.

\begin{tabular}{|c|c|c|c|}
\hline Principal reason for visit and RVC code ${ }^{1}$ & & $\begin{array}{l}\text { Number of visits } \\
\text { (standard error) } \\
\text { in thousands }\end{array}$ & $\begin{array}{l}\text { Percent distribution } \\
\text { (standard error) }\end{array}$ \\
\hline All visits, ages $15-64$ & $\ldots$ & $88,229(6,797)$ & $100.0 \ldots$ \\
\hline \multicolumn{2}{|l|}{ Female } & $50,846(4,025)$ & $57.6(0.7)$ \\
\hline Stomach and abdominal pain, cramps and spasms & S545 & $6,548(593)$ & $7.4(0.4)$ \\
\hline Chest pain and related symptoms & S050 & $2,990(343)$ & $3.4(0.3)$ \\
\hline Headache, pain in head & S210 & $1,988(205)$ & $2.3(0.2)$ \\
\hline Pain, specified site not referable to a specific body system & S055 & $1,493(214)$ & $1.7(0.2)$ \\
\hline Cough & S440 & $1,461(278)$ & $1.7(0.3)$ \\
\hline Back symptoms & S905 & $1,400(184)$ & $1.6(0.2)$ \\
\hline Shortness of breath & S415 & $1,314(179)$ & $1.5(0.2)$ \\
\hline Symptoms referable to throat & S455 & $1,216(159)$ & $1.4(0.1)$ \\
\hline Nausea & S525 & $1,131(257)$ & $1.3(0.2)$ \\
\hline Problems of pregnancy & S790 & $1,111(205)$ & $1.3(0.2)$ \\
\hline All other reasons ${ }^{2}$ & $\ldots$ & $30,194(2,323)$ & $34.2(0.5)$ \\
\hline \multicolumn{2}{|l|}{ Male } & $37,384(2,890)$ & $42.4(0.7)$ \\
\hline Stomach and abdominal pain, cramps and spasms & S545 & $2,933(354)$ & $3.3(0.3)$ \\
\hline Chest pain and related symptoms & S050 & $1,957(214)$ & $2.2(0.2)$ \\
\hline Pain, specified site not referable to a specific body system & S055 & $1,399(188)$ & $1.6(0.2)$ \\
\hline Back symptoms & S905 & $1,359(203)$ & $1.5(0.2)$ \\
\hline Shortness of breath & S415 & $1,062(204)$ & $1.2(0.2)$ \\
\hline Leg symptoms & S920 & $1,028(184)$ & $1.2(0.2)$ \\
\hline Cough & S440 & 861 (136) & $1.0(0.2)$ \\
\hline Symptoms of teeth and gums & S500 & $732(146)$ & $0.8(0.1)$ \\
\hline Laceration or cut of upper extremity & $\mathrm{J} 225$ & $728(108)$ & $0.8(0.1)$ \\
\hline Injury, other and unspecified of head, neck, and face & $\mathrm{J} 505$ & $692(143)$ & $0.8(0.1)$ \\
\hline All other reasons ${ }^{2}$ & $\ldots$ & $24,633(1,873)$ & $27.9(0.7)$ \\
\hline \multirow{2}{*}{\multicolumn{2}{|c|}{ All visits, ages 65 and over }} & $22,379(2,068)$ & $100.0 \ldots$ \\
\hline & & $13,198(1,225)$ & $59.0(1.6)$ \\
\hline Stomach and abdominal pain, cramps, and spasms & S545 & $913(166)$ & $4.1(0.6)$ \\
\hline Accident, not otherwise specified & S050 & $756(115)$ & $3.4(0.5)$ \\
\hline Chest pain and related symptoms (not referable to body systems) & S415 & $751(118)$ & $3.4(0.4)$ \\
\hline Shortness of breath & J810 & $503(126)$ & $2.2(0.5)$ \\
\hline Vertigo-dizziness & S020 & $428(115)$ & $1.9(0.5)$ \\
\hline General weakness & S920 & $367(82)$ & $1.6(0.3)$ \\
\hline Leg symptoms & S225 & $352(76)$ & $1.6(0.3)$ \\
\hline Cough & S595 & * $\ldots$ & $1.5(0.6)$ \\
\hline Nausea & S095 & $340(77)$ & $1.5(0.3)$ \\
\hline \multicolumn{4}{|l|}{ Other symptoms or problems relating to psychological and } \\
\hline All other reasons ${ }^{2}$ & $\ldots$ & $8,115(790)$ & $36.3(1.2)$ \\
\hline Male & $\cdots$ & $9,181(962)$ & $41.0(1.6)$ \\
\hline Shortness of breath & S415 & $661(115)$ & $3.0(0.4)$ \\
\hline Chest pain and related symptoms & S050 & $540(82)$ & $2.4(0.3)$ \\
\hline Stomach and abdominal pain, cramps and spasms & S545 & $510(100)$ & $2.3(0.4)$ \\
\hline General weakness & S020 & *492 (161) & $2.2(0.6)$ \\
\hline Leg symptoms & S920 & *313 (94) & $1.4(0.4)$ \\
\hline Disorders of motor functions & S095 & *... & $1.2(0.3)$ \\
\hline Pain, specified site not referable to a specific body system & S055 & *... & $1.2(0.4)$ \\
\hline Vertigo-dizziness & S225 & * $\ldots$ & $0.9(0.2)$ \\
\hline $\begin{array}{l}\text { "Other symptoms or problems relating to psychological and } \\
\text { mental disorders, not elsewhere classified" }\end{array}$ & S165 & * $\ldots$ & $0.9(0.2)$ \\
\hline Cough & S440 & * $\ldots$ & $0.9(0.2)$ \\
\hline All other reasons ${ }^{2}$ & $\ldots$ & $5,522(564)$ & $24.7(1.1)$ \\
\hline
\end{tabular}

... Category not applicable.

*.. Category not applicable.

${ }^{1}$ Reason for visit is based on the patient's own words and coded according to "A Reason for Visit Classification for Ambulatory Care" (RVC). National Center for Health Statistics. Vital Health Stat 2(78). 1979. See also the 2017 National Hospital Ambulatory Medical Care Survey public-use data file documentation, available from: https://ftp.cdc.gov/pub/Health_Statistics/NCHS/ Dataset_Documentation/NHAMCS/doc17_ed-508.pdf.

Includes all other reasons not listed above, as well as unknown and blanks.

NOTES: Numbers may not add to totals because of rounding. Visit estimates are not presented if they are based on fewer than 30 cases in the sample data, in which case only an asterisk is shown. Visit estimates based on 30 cases or more include an asterisk if the relative standard error of the estimate exceeds $30 \%$. Proportion estimates are not presented if they are unreliable based on the procedure specified in "National Center for Health Statistics Data Presentation Standards for Proportions" (https://www.cdc.gov/nchs/data/series/sr_02/sr02_175.pdf), in which case only an asterisk is shown.

SOURCE: NCHS, National Hospital Ambulatory Medical Care Survey, 2017. 
Table 11. Primary diagnosis at emergency department visits, by major disease category: United States, 2017

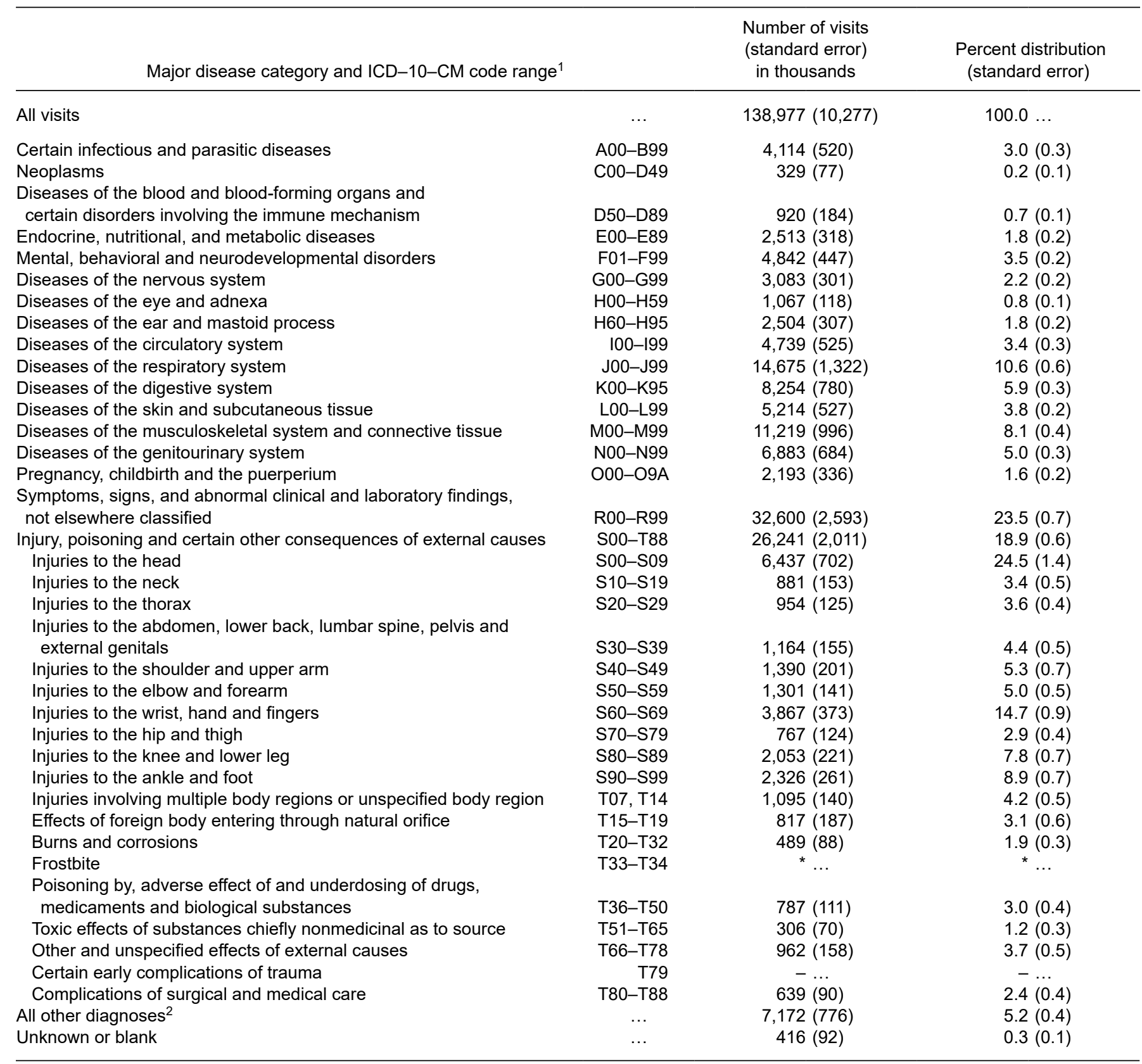

... Category not applicable.

* Estimate does not meet NCHS standards of reliability.

- Quantity zero.

${ }^{1}$ Based on the International Classification of Diseases, 10th Revision, Clinical Modification (ICD-10-CM). However, certain codes have been combined in this table to better describe the utilization of ambulatory care services. Web tables presenting diagnosis estimates before 2016 used the International Classification of Diseases, Ninth Revision, Clinical Modification (ICD-9-CM) coding system. Due to substantial differences between ICD-9-CM and ICD-10-CM, caution is advised when comparing diagnosis estimates in this table with those from before 2016.

${ }^{2}$ Includes certain conditions originating in the perinatal period (P00-P96), congenital malformations, deformations and chromosomal abnormalities (Q00-Q99), external causes of morbidity (V00-Y99), and factors influencing health status and contact with health services (Z00-Z99).

NOTES: Numbers may not add to totals because of rounding. Visit estimates are not presented if they are based on fewer than 30 cases in the sample data, in which case only an asterisk is shown. Proportion estimates are not presented if they are unreliable based on the procedure specified in "National Center for Health Statistics Data Presentation Standards for Proportions" (https://www.cdc.gov/nchs/data/series/sr_02/sr02_175.pdf), in which case only an asterisk is shown.

SOURCE: NCHS, National Hospital Ambulatory Medical Care Survey, 2017. 
Table 12. Annual number and percent distribution of emergency department visits, by diagnosis group: United States, 2017

\begin{tabular}{|c|c|c|}
\hline Primary diagnosis group ${ }^{1}$ & $\begin{array}{l}\text { Number of visits } \\
\text { (standard error) } \\
\text { in thousands }\end{array}$ & $\begin{array}{l}\text { Percent distribution } \\
\text { (standard error) }\end{array}$ \\
\hline \multicolumn{3}{|l|}{ Certain infectious and parasitic diseases } \\
\hline Septicemia (sepsis) & $405(102)$ & $0.3(0.1)$ \\
\hline Human immunodeficiency virus syndrome (HIV, HIV+, HIV positive) & ${ }^{*} \ldots$ & ${ }^{*} \ldots$ \\
\hline Sexually transmitted infections (STIs) excluding viral hepatitis and HIV & * $\ldots$ & $0.1(0.0)$ \\
\hline Unspecified viral infection & $1,309(225)$ & $0.9(0.1)$ \\
\hline Dermatophytosis & * $\ldots$ & $0.1(0.0)$ \\
\hline Candidiasis & ${ }^{*} \ldots$ & $0.1(0.0)$ \\
\hline Other systemic infectious and parasitic diseases & $1,860(258)$ & $1.3(0.1)$ \\
\hline \multicolumn{3}{|l|}{$\begin{array}{l}\text { Diseases of the blood and blood-forming organs and } \\
\text { certain disorders involving the immune mechanism }\end{array}$} \\
\hline Anemias & $778(151)$ & $0.6(0.1)$ \\
\hline $\begin{array}{l}\text { Other diseases of the blood and blood-forming organs and } \\
\text { certain disorders involving the immune mechanism }\end{array}$ & * $\ldots$ & $0.1(0.0)$ \\
\hline \multicolumn{3}{|l|}{ Endocrine, nutritional and metabolic diseases } \\
\hline Acquired hypothyroidism & * ... & ${ }^{*} \ldots$ \\
\hline Disorders of thyroid gland, excluding acquired hypothyroidism & * $\ldots$ & ${ }^{*} \ldots$ \\
\hline Type 1 diabetes mellitus & *. & $0.1(0.0)$ \\
\hline Type 2 diabetes mellitus or unspecified & $653(99)$ & $0.5(0.1)$ \\
\hline Other types of diabetes mellitus & * $\ldots$ & $0.1(0.0)$ \\
\hline Other disorders of endocrine glands & ${ }^{*} \ldots$ & $0.2(0.0)$ \\
\hline Obesity & * $\ldots$ & $0.1(0.1)$ \\
\hline Cocaine-related disorders & * $\ldots$ & $0.0(0.0)$ \\
\hline Nicotine dependence & * $\ldots$ & $0.0(0.0)$ \\
\hline Other drug-related disorders excluding other drug-related dementia & $418(89)$ & $0.3(0.1)$ \\
\hline Schizophrenia & $109(29)$ & $0.1(0.0)$ \\
\hline Non-mood psychoses, excluding schizophrenia & $278(61)$ & $0.2(0.0)$ \\
\hline Bipolar disorders, excluding those with depression & $236(59)$ & $0.2(0.0)$ \\
\hline Bipolar disorders, with depression & * ... & $0.0(0.0)$ \\
\hline $\begin{array}{l}\text { Depressive disorders, excluding bipolar depression and } \\
\text { adjustment reaction with depressed mood }\end{array}$ & $632(108)$ & $0.5(0.1)$ \\
\hline Dysthymic disorder & * $\ldots$ & * $\ldots$ \\
\hline $\begin{array}{l}\text { Acute reaction to stress and adjustment reaction, excluding } \\
\text { those with depressed mood }\end{array}$ & ${ }^{*} \ldots$ & $0.1(0.0)$ \\
\hline Acute reaction to stress and adjustment reaction with depressed mood & ${ }^{*} \ldots$ & $0.0(0.0)$ \\
\hline Eating disorders & * $\ldots$ & *... \\
\hline Impulse disorders & * $\ldots$ & * $\ldots$ \\
\hline $\begin{array}{l}\text { Other mood disorders, nonpsychotic mental disorders, behavioral } \\
\text { syndromes, and disorders of adult personality and behavior }\end{array}$ & $1,098(149)$ & $0.8(0.1)$ \\
\hline Attention-deficit/hyperactivity disorders & ${ }^{*} \ldots$ & $0.0(0.0)$ \\
\hline Oppositional defiant disorder & * & * ... \\
\hline Conduct disorders, excluding oppositional defiant disorder & * $\ldots$ & $0.1(0.0)$ \\
\hline Autism spectrum disorder & * $\ldots$ & * $\ldots$ \\
\hline Other mental disorders & * $\ldots$ & $0.2(0.0)$ \\
\hline
\end{tabular}


Table 12. Annual number and percent distribution of emergency department visits, by diagnosis group: United States, 2017-Con.

Number of visits

Primary diagnosis group ${ }^{1}$

(standard error)

in thousands

Percent distribution

Diseases of the nervous system

Alzheimer's disease

Migraine

Transient cerebral ischemic attacks and related syndromes

Sleep disorders, excluding sleep apnea (adult, pediatric, obstructive) and non-organic sleep disorders

Obstructive sleep apnea (adult, pediatric) and sleep apnea, not

otherwise specified

Carpal tunnel syndrome

Other disorders of the nervous system

\begin{tabular}{|c|c|}
\hline${ }^{*} \ldots$ & $0.0(0.0)$ \\
\hline 928 (149) & $0.7(0.1)$ \\
\hline * $\ldots$ & $0.1(0.0)$ \\
\hline * $\ldots$ & * $\ldots$ \\
\hline * $\ldots$ & * ... \\
\hline${ }^{*} \ldots$ & $0.0(0.0)$ \\
\hline $1,888(221)$ & $1.4(0.1)$ \\
\hline * $\ldots$ & $0.1(0.0)$ \\
\hline 529 (84) & $0.4(0.1)$ \\
\hline${ }^{*} \ldots$ & * $\ldots$ \\
\hline${ }^{*} \ldots$ & *. \\
\hline 441 (91) & $0.3(0.1)$ \\
\hline
\end{tabular}

Inflammation and disorders of eyelid

Conjunctivitis

Glaucoma

Disorders of refraction and accommodation

Other disorders of the eye and adnexa

Diseases of the ear and mastoid process

Disorders of external ear

Otitis media and eustachian tube disorders

$447(104)$

$0.3(0.1)$

$1,460(208)$

$1.1(0.1)$

Other disorders of the ear and mastoid process

$597(104)$

$0.4(0.1)$

Heart valve disorders

Diseases of the circulatory system

Essential hypertension

Hypertensive heart disease with heart failure

Hypertensive chronic kidney disease with stage 1 through stage 4

chronic kidney disease or unspecified chronic kidney disease

Hypertensive chronic kidney disease with stage 5 chronic kidney disease or end-stage renal disease (ESRD)

Hypertensive heart and chronic kidney disease without heart failure with stage 1 through 4 chronic kidney disease or unspecified chronic kidney disease

Hypertensive heart and chronic kidney disease with heart failure with stage 5 chronic kidney disease or end stage renal disease

Secondary hypertension

Hypertensive crisis

Angina pectoris not stated as with chronic ischemic heart disease

Acute myocardial infarction (AMI)

Other acute and subacute ischemic heart disease

Coronary atherosclerosis and other chronic ischemic heart disease

(with angina pectoris)

Pulmonary heart disease and diseases of pulmonary circulation

Conduction disorders

Cardiac dysrhythmias, excluding ventricular fibrillation

Cardiac arrest and ventricular fibrillation

Heart failure, non-hypertensive

Pericarditis, endocarditis, myocarditis and cardiomyopathy

Other and ill-defined heart disease

Cerebrovascular disease

Diseases of the arteries, arterioles and capillaries

Varicose veins of lower extremity

Other disorder of circulatory system

\begin{tabular}{|c|c|}
\hline * & * \\
\hline $1,272(226)$ & $0.9(0.1)$ \\
\hline${ }^{*} \ldots$ & $0.0(0.0)$ \\
\hline * $\ldots$ & * $\ldots$ \\
\hline * $\ldots$ & ${ }^{*} \ldots$ \\
\hline * $\ldots$ & * $\ldots$ \\
\hline * $\ldots$ & ${ }^{*} \ldots$ \\
\hline * $\ldots$ & * \\
\hline * $\ldots$ & $0.1(0.1)$ \\
\hline${ }^{*} \ldots$ & $0.1(0.1)$ \\
\hline $260(59)$ & $0.2(0.0)$ \\
\hline * ... & $0.1(0.0)$ \\
\hline${ }^{*} \ldots$ & $0.0(0.0)$ \\
\hline * $\ldots$ & $0.1(0.0)$ \\
\hline * $\ldots$ & $0.0(0.0)$ \\
\hline $622(104)$ & $0.4(0.1)$ \\
\hline * & $0.1(0.0)$ \\
\hline 524 (124) & $0.4(0.1)$ \\
\hline * $\ldots$ & $0.0(0.0)$ \\
\hline * $\ldots$ & * $\ldots$ \\
\hline 492 (108) & $0.4(0.1)$ \\
\hline * $\ldots$ & $0.1(0.0)$ \\
\hline * $\ldots$ & $0.0(0.0)$ \\
\hline 547 (103) & $0.4(0.1)$ \\
\hline
\end{tabular}

See footnotes at end of table. 
Table 12. Annual number and percent distribution of emergency department visits, by diagnosis group: United States, 2017-Con.

Number of visits

Other disorder of circulatory system

(standard error)

in thousands

Percent distribution

Diseases of the respiratory system

Streptococcal phayrngitis and tonsillitis

Acute sinusitis

Acute pharyngitis, except streptococcal pharyngitis

Acute tonsillitis, except streprococcal tonsillitis

Influenza

Pneumonia

Acute bronchitis and bronchiolitis

Other acute respiratory infections

Allergic rhinitis

Chronic sinusitis

Chronic and unspecified bronchitis

Bronchiectasis, emphysema and other chronic obstructive pulmonary

disease, including chronic obstructive asthma

Asthma, excluding chronic obstructive asthma

Respiratory failure

Other diseases of the respiratory system

$\begin{array}{rr}1,048(162) & 0.8(0.1) \\ 415(96) & 0.3(0.1) \\ 1,186(165) & 0.9(0.1) \\ * \ldots & 0.2(0.1) \\ 1,283(317) & 0.9(0.2) \\ 1,286(145) & 0.9(0.1) \\ 1,377(210) & 1.0(0.1) \\ 3,415(386) & 2.5(0.2) \\ * \ldots & 0.1(0.0) \\ * 242(77) & 0.2(0.1) \\ 697(108) & 0.5(0.1) \\ & \\ 923(122) & 0.7(0.1) \\ 1,564(203) & 1.1(0.1) \\ * \ldots & 0.2(0.1) \\ 597(94) & 0.4(0.1)\end{array}$

Diseases of the digestive system

Diseases of the teeth and supporting structures, excluding dentofacial anomalies and disorders of the jaw

Esophagitis without gastroesophageal reflux disease

Gastroesophageal reflux disease (with esophagitis)

Other diseases of the esophagus

Ulcers of stomach and small intestine

Gastritis and duodentitis

Appendicitis

Diaphragmatic hernia

Hernias of abdominal cavity, except diaphragmatic hernia

Crohn's disease and ulcerative colitis

Other and unspecified noninfectious enteritis and colitis

Intestinal obstructions

Diverticula of intestine

Constipation

Anal and rectal diseases

Hemorrhoids and perianal venous thrombosis

Alcoholic liver disease

Other diseases of the liver

Disorders of gallbladder and biliary tract

Diseases of the pancreas

Unspecified gastrointestinal bleeding

Other diseases of the digestive system

$1,737(266)$

* ...

$258(69)$

*...

*...

$437(97)$

*...

*...

$290(69)$

*...

$1,000(152)$

* ...

270 (63)

934 (136)

418 (95)

* ...

* $\ldots$

* $\cdots$

528 (119)

$326(75)$

483 (118)

* ...

$1,606(202)$

1,228 (190)

557 (103)

*277 (92)

* ...

349 (94)

$533(95)$

*...

* $\ldots$

*...

${ }^{*} \ldots$

*...

$414(73)$
$1.2(0.2)$

$0.0(0.0)$

$0.2(0.0)$

* ...

$0.0(0.0)$

$0.3(0.1)$

$0.2(0.1)$

* ...

$0.2(0.1)$

$0.1(0.0)$

$0.7(0.1)$

$0.1(0.0)$

$0.2(0.0)$

$0.7(0.1)$

$0.3(0.1)$

$0.1(0.0)$

$0.1(0.0)$

$0.1(0.0)$

$0.4(0.1)$

$0.2(0.1)$

$0.3(0.1)$

$0.1(0.0)$

$1.2(0.1)$

$0.9(0.1)$

$0.4(0.1)$

$0.2(0.1)$

$0.1(0.0)$

$0.3(0.1)$

$0.4(0.1)$

* ...

*...

$0.0(0.0)$

* ...

$0.3(0.0)$

See footnotes at end of table. 
Table 12. Annual number and percent distribution of emergency department visits, by diagnosis group: United States, 2017-Con.

\begin{tabular}{ccc}
\hline & Number of visits & \\
(standard error) & Percent distribution \\
Primary diagnosis group ${ }^{1}$ & in thousands & (standard error)
\end{tabular}

Diseases of the musculoskeletal system and connective tissue

Rheumatoid arthritis

Infectious and inflammatory arthropathies, excluding

rheumatoid and juvenile arthritis

Osteoarthritis

Acquired deformities of fingers and toes

Internal derangement of knee

Other joint disorders

Spinal stenosis

Spondylopathies, excluding spinal stenosis

Intervertebral disc disorders

Low back pain, unspecified

Other conditions of the spine and back, excluding low back pain

Synovitis and tenosynovitis

Soft tissue disorders related to use, overuse and pressure

Ganglion and cyst of synovium, tendon and bursa

Myalgia and myositis, unspecified

Disorders of bone and cartilage, excluding osteoporosis

Other diseases of the musculoskeletal system and connective tissue

Diseases of the genitourinary system

Nephritis, nephrotic syndrome, and nephrosis

Infections of kidney

Acute kidney failure

Chronic kidney disease, excluding end stage renal disease (ESRD)

End stage renal disease (ESRD)

Unspecified kidney failure, including uremia, not otherwise specified

Calculus of kidney and ureter

Cystitis

Urinary tract infection, site not specified

Other diseases of the urinary system

Benign prostatic hyperplasia (BPH)

Disorders of prepuce

Other disorders of male genital organs

Unspecified lump or mass in breast

Disorders of the breast, excluding unspecified lump or mass

Inflammatory disease of female pelvic organs

Endometriosis

Genital prolapse (female)

Other noninflammatory disorders of female genital organs

Disorders of menstruation and abnormal bleeding

Menopausal and postmenopausal disorders

Other disorders of female genital tract

Complications of pregnancy, childbirth, and the puerperium

Non-uterine pregnancy

Missed abortion

Supervision of high-risk pregnancy

Pre-existing diabetes mellitus, types 1 and 2, complicating pregnancy

Early or threatened labor

Other complications of pregnancy

Other complications of pregnancy, childbirth and the puerperium

Sleep apnea of newborn

Certain other conditions originating in the perinatal period

Congenital anomalies

Congenital anomalies (standard error)

thousands (standard error)

$\begin{aligned} & * \\ & \cdots \\ * & \ldots \\ 282 & (66) \\ * & \cdots \\ & * \ldots \\ 2,734 & (322) \\ & * \cdots \\ & * \cdots \\ & * \ldots \\ 1,493 & (205)\end{aligned}$

$1,493(205)$

$2,952(321)$

* ...

$367(96)$

*...

*

*...

$2,419(253)$

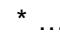

388 (98)

*...

* ...

* ...

*...

764 (120)

646 (146)

2,070 (239)

511 (99)

*...

*...

357 (66)

*...

*...

$335(62)$

* $\ldots$

*...

452 (93)

506 (70)

*...

*...

*...

* ...

* $\cdots$

*...

*70 (27)

*

$1,917(320)$

*...

* ...

* ...
*...

$0.1(0.0)$

$0.2(0.0)$

* $\ldots$

$2.0(0.2)$

$0.0(0.0)$

$0.1(0.0)$

$1.1(0.1)$

$2.1(0.2)$

$0.1(0.0)$

$0.3(0.1)$

* ...

$0.1(0.0)$

$0.1(0.0)$

$1.7(0.1)$

* ..

$0.3(0.1)$

$0.2(0.0)$

$0.0(0.0)$

$0.0(0.0)$

* ...

$0.6(0.1)$

$0.5(0.1)$

$1.5(0.1)$

$0.4(0.1)$

$0.0(0.0)$

$0.1(0.0)$

$0.3(0.0)$

* ...

$0.1(0.0)$

$0.2(0.0)$

* ...

* ...

$0.3(0.1)$

$0.4(0.1)$

*

$0.1(0.0)$

$0.0(0.0)$

* ...

$0.0(0.0)$

* ...

$0.1(0.0)$

$0.1(0.0)$

$1.4(0.2)$

*

$0.1(0.0)$

$0.1(0.0)$

See footnotes at end of table. 
Table 12. Annual number and percent distribution of emergency department visits, by diagnosis group: United States, 2017-Con.

Number of visits

Primary diagnosis group ${ }^{1}$

(standard error)

Percent distribution

in thousands

(standard error)

Symptoms, signs, and ill-defined conditions

Abnormal heart beat and heart sounds

$641(106)$

$345(78)$

$951(149)$

Cough, unspecified

Dyspnea and respiratory abnormalities

Chest pain

Abdominal pain

Unspecified jaundice, edema and other non-specific skin symptoms

Hematuria

Symptoms involving the urinary system, excluding hematuria and

urinary incontinence

Vertigo and lightheadedness

Fever of other and unknown origin

Headache

Malaise and fatigue

Syncope and collapse

Convulsions and seizures, not elsewhere classified

Other symptoms, signs, abnormal findings and ill-defined conditions

Injury and poisoning

Injury of eye and orbit

Contusions (bruise, hematoma)

Superficial injuries, excluding contusions (abrasion, blister, external constriction, splinter, superficial bite)

Open wound of head

Open wound of wrist, hand and fingers

Open wound of hip and lower limb

Open wound, excluding head, hand, fingers, lower limb and

internal organs

Traumatic fracture of shoulder and upper arm (clavicle, scapula,

humerus)

Traumatic fracture of forearm (radius and ulna)

Traumatic fracture of wrist, hand and fingers (carpal, metacarpals, phalanges)

Traumatic fracture of hip (head and neck of femur)

Traumatic fracture of ankle (medial malleolus, lateral malleolus, bimalleolar, trimalleolar)

Traumatic fracture of leg, foot and toes, excluding hip and ankle (femur, patella, tibia, fibula, tarsals, metatarsals, phalanges)

Other traumatic fractures (skull, facial bones, vertebrae, ribs,

sternum, pelvis)

Tear of medial meniscus, current injury

Dislocations, excluding tear of medial meniscus

Sprains and strains of neck

Sprains and strains of back

Sprains and strains of wrist and hand

Sprains and strains of knee

Strains and sprains of ankle

Sprain and strains, excluding neck, back, wrist, hand, knee, ankle

Concussion

Intracranial injury, excluding concussion

Internal injury of chest, abdomen and pelvis

Other injuries, excluding burns and poisonings

Burns and corrosions, external and internal, excluding sunburn

Poisoning (overdose or wrong substance given or taken in error) due to drugs and biological substances, accidental (unintentional)

Poisoning (overdose or wrong substance given or taken in error) due to drugs and biological substances, intentional self-harm
$1,246(153)$

$5,159(548)$

$6,954(656)$

$1,290(167)$

$400(90)$

$696(109)$

$932(127)$

$1,720(301)$

$1,918(227)$

$716(132)$

$1,066(149)$

$632(100)$

7,932 (755)

413 (93)

3,150 (329)

1,209 (220)

$1,752(248)$

$1,610(217)$

824 (135)

385 (85)

464 (86)

578 (86)

750 (132)

* ...

* ...

674 (107)

998 (173)

* ...

391 (93)

720 (133)

768 (139)

551 (103)

333 (72)

872 (138)

691 (101)

689 (170)

* ...

*...

4,635 (530)

489 (88)

323 (61)

281 (75)
$0.5(0.1)$

$0.2(0.1)$

$0.7(0.1)$

$0.9(0.1)$

$3.7(0.3)$

$5.0(0.3)$

$0.9(0.1)$

$0.3(0.1)$

$0.5(0.1)$

$0.7(0.1)$

$1.2(0.2)$

$1.4(0.1)$

$0.5(0.1)$

$0.8(0.1)$

$0.5(0.1)$

$5.7(0.2)$

$0.3(0.1)$

$2.3(0.2)$

$0.9(0.1)$

$1.3(0.2)$

$1.2(0.1)$

$0.6(0.1)$

$0.3(0.1)$

$0.3(0.1)$

$0.4(0.1)$

$0.5(0.1)$

$0.2(0.1)$

$0.1(0.0)$

$0.5(0.1)$

$0.7(0.1)$

* ...

$0.3(0.1)$

$0.5(0.1)$

$0.6(0.1)$

$0.4(0.1)$

$0.2(0.1)$

$0.6(0.1)$

$0.5(0.1)$

$0.5(0.1)$

$0.1(0.0)$

$0.1(0.0)$

$3.3(0.3)$

$0.4(0.1)$

$0.2(0.0)$

$0.2(0.1)$

See footnotes at end of table. 
Table 12. Annual number and percent distribution of emergency department visits, by diagnosis group: United States, 2017-Con.

\begin{tabular}{|c|c|c|}
\hline Primary diagnosis group ${ }^{1}$ & $\begin{array}{l}\text { Number of visits } \\
\text { (standard error) } \\
\text { in thousands }\end{array}$ & $\begin{array}{l}\text { Percent distribution } \\
\text { (standard error) }\end{array}$ \\
\hline \multicolumn{3}{|l|}{$\begin{array}{l}\text { Poisoning (overdose or wrong substance given or taken in error) due to } \\
\text { drugs and biological substances, undetermined intent }\end{array}$} \\
\hline \multicolumn{2}{|l|}{ Adverse effects (of correct substance properly administered) of drugs } & $0.1(0.0)$ \\
\hline Toxic effects of substances chiefly non-medical, intentional self-harm & * ... & *... \\
\hline Toxic effects of substances chiefly non-medical, undetermined & *. & * \\
\hline Other and unspecified effects of external causes & $962(158)$ & $0.7(0.1)$ \\
\hline Complications of surgical and medical care & $937(116)$ & $0.7(0.1)$ \\
\hline \multicolumn{3}{|l|}{ External-cause codes } \\
\hline Land transport accidents & * ... & * $\ldots$ \\
\hline \multicolumn{3}{|l|}{ Accidental (unintentional) injury due to contact with glass or other sharp } \\
\hline \multicolumn{3}{|l|}{ Accidental (unintentional) injury due to foreign body or object entering } \\
\hline Accidental (unintentional) injury due to exposure to radiation & * $\cdots$ & * $\cdots$ \\
\hline \multicolumn{3}{|l|}{ Accidental (unintentional) injury due to smoke, fire or flames, heat and } \\
\hline Accidental (unintentional) injury due to other and unspecified means & * $\ldots$ & *... \\
\hline Intentional self harm by cutting with sharp or piercing instrument & * $\ldots$ & * $\ldots$ \\
\hline Assault by bodily force & * $\ldots$ & ${ }^{*} \ldots$ \\
\hline Assault by unspecified means & * $\ldots$ & * $\ldots$ \\
\hline Activity & * $\ldots$ & * $\ldots$ \\
\hline \multicolumn{3}{|l|}{ Supplementary classifications } \\
\hline \multicolumn{3}{|l|}{ Encounter for general adult medical examminations, including routine } \\
\hline Other encounter related to pregnancy, excluding incidental pregnancy & * $\ldots$ & $0.1(0.0)$ \\
\hline \multicolumn{3}{|l|}{$\begin{array}{l}\text { Potential health hazards related to personal and family history, excluding } \\
\text { personal history of pulmonary embolism and personal history of } \\
\text { cerebral infarction or transient ischemic attack (TIA) without residual }\end{array}$} \\
\hline Other factors influencing health status and contact with health services & $1,434(188)$ & $1.0(0.1)$ \\
\hline Uncodable entries $^{3}$ & $2,764(535)$ & $2.0(0.4)$ \\
\hline Unknown or blank & $416(92)$ & $0.3(0.1)$ \\
\hline
\end{tabular}

Category not applicable.

* Estimate does not meet NCHS standards of reliability.

0.0 Quantity more than zero but less than 0.05 .

${ }^{1}$ Based on the International Classification of Diseases, 10th Revision, Clinical Modification (ICD-10-CM). Codes have been combined according to the NCHS Diagnosis Master Category List (DMCL). For a list of ICD-10-CM codes corresponding to a specific diagnosis group, refer to the DMCL document, available from: https://www.cdc.gov/nchs/data/ahcd/Reclass ICD 10 CM tables.pdf. Web tables presenting diagnosis estimates before 2016 used the International Classification of Diseases, Ninth Revision, Clinical Modification (ICD-9-CM) coding system. Due to substantial differences between ICD-9-CM and ICD-10-CM, caution is advised when comparing diagnosis estimates in this table with those from before 2016 .

${ }^{2}$ Diagnosis groups for this chapter are not shown due to low sample sizes.

${ }^{3}$ Includes illegible diagnosis, left before being seen, walked out, eloped, left against medical advice, and entries of "none," "no diagnosis," "no disease," and "healthy" as the only entry in the diagnosis item.

NOTES: Numbers may not add to totals because of rounding. Visit estimates are not presented if they are based on fewer than 30 cases in the sample data, in which case only an asterisk is shown. Visit estimates based on 30 cases or more include an asterisk if the relative standard error of the estimate exceeds $30 \%$. Proportion estimates are not presented if they are unreliable based on the procedure specified in "National Center for Health Statistics Data Presentation Standards for Proportions" (https://www.cdc.gov/nchs/data/series/sr_02/sr02 175.pdf), in which case only an asterisk is shown.

SOURCE: NCHS, National Hospital Ambulatory Medical Care Survey, 2017. 
Table 13. Presence of chronic conditions at emergency department visits: United States, 2017

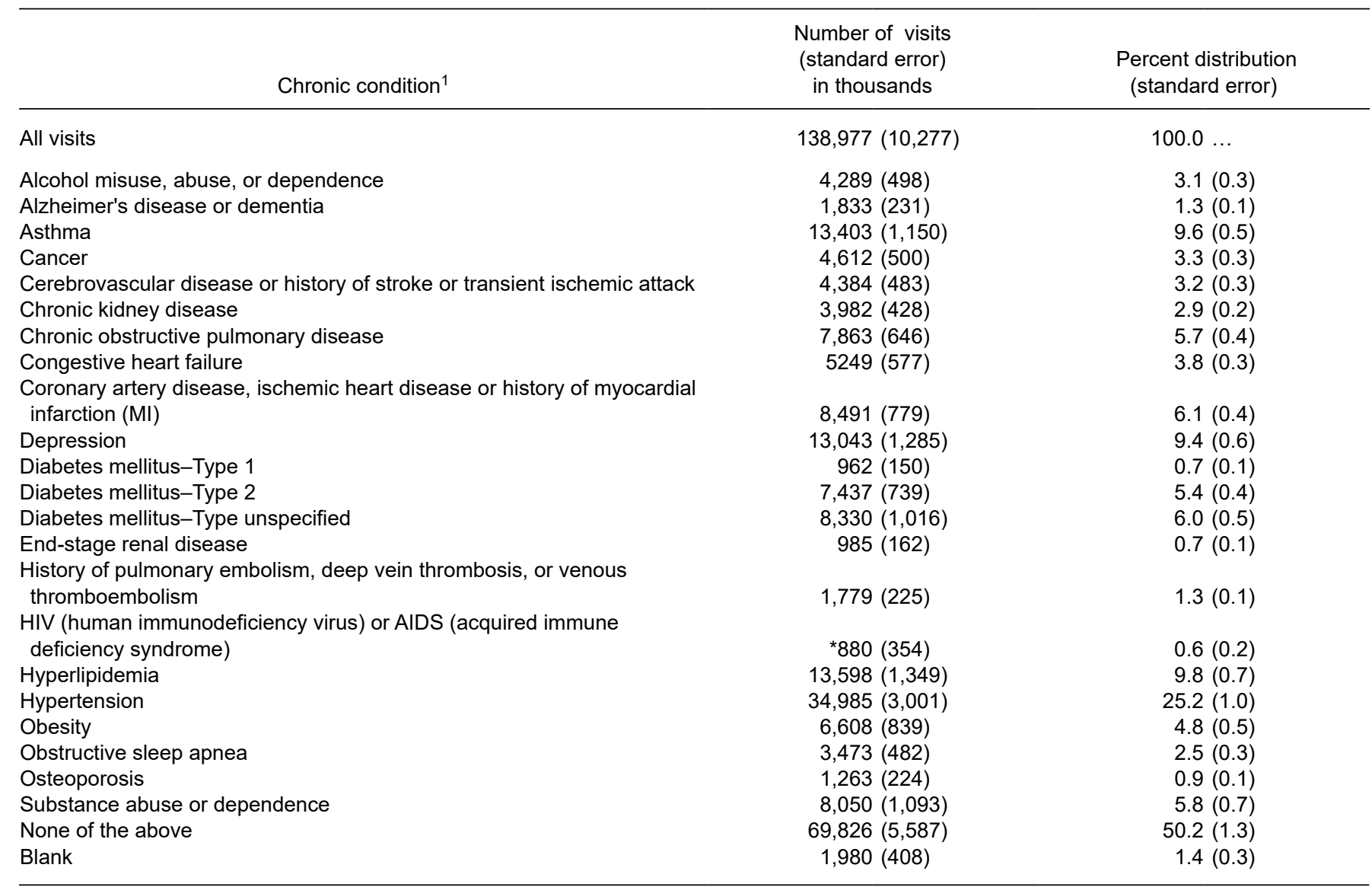

... Category not applicable.

"Presence of chronic conditions was based on the checklist of chronic conditions and reported diagnoses.

NOTES: Numbers may not add to totals because of rounding. Total exceeds "All visits" and percentage exceeds $100 \%$ because more than one chronic condition may be reported per visit. SOURCE: NCHS, National Hospital Ambulatory Medical Care Survey, 2017. 
Table 14. Injury visits to emergency departments, by selected patient and hospital characteristics: United States, 2017

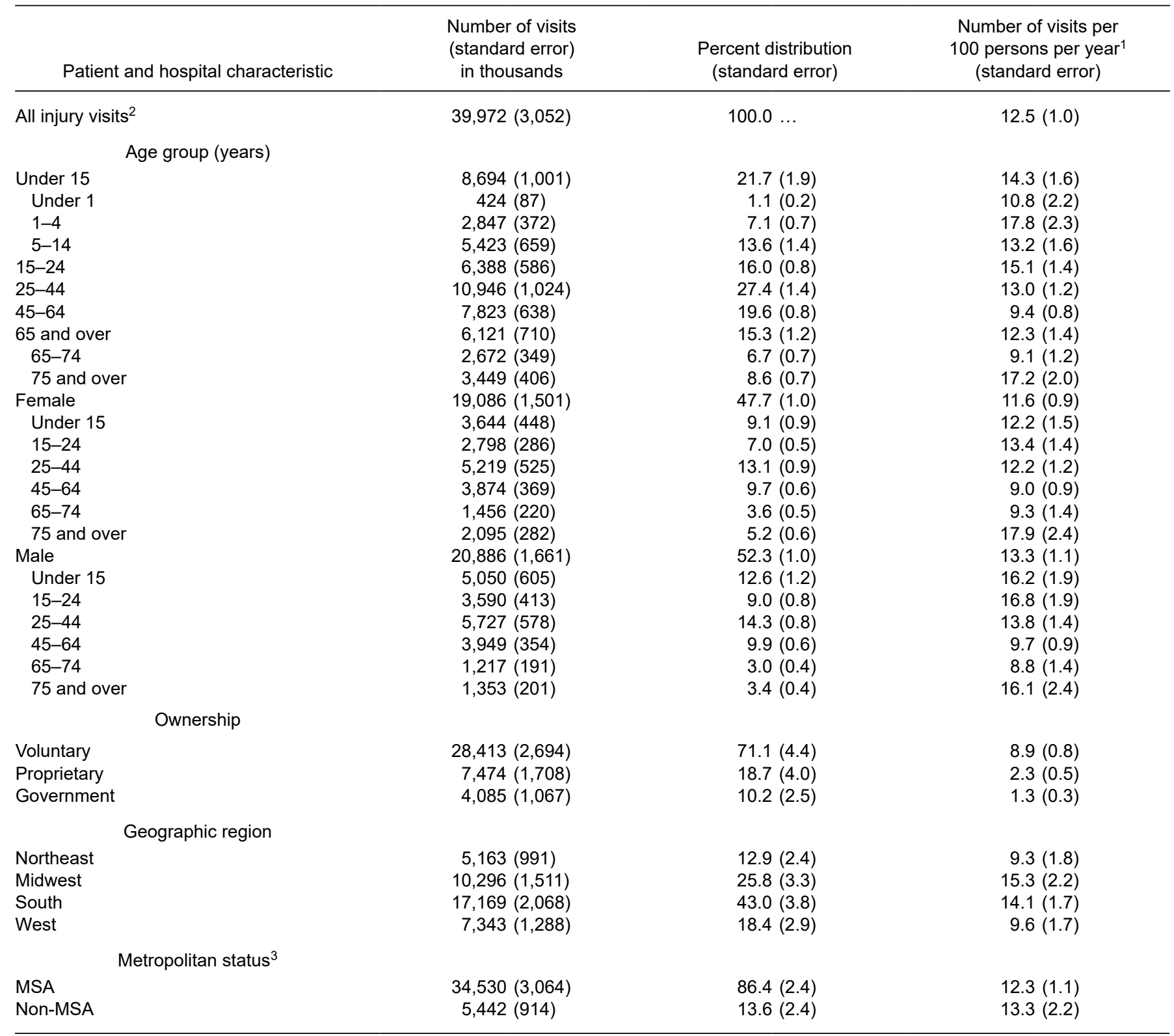

... Category not applicable.

${ }^{1}$ Visit rates for age, sex, and region are based on the July 1, 2017, set of estimates of the U.S. civilian noninstitutionalized population as developed by the U.S. Census Bureau, Population Division.

${ }^{2}$ The definition of injury changed in 2016 due to the switch from the International Classification of Diseases, Ninth Revision, Clinical Modification (ICD-9-CM) coding system for diagnosis data to the International Classification of Diseases, 10th Revision, Clinical Modification (ICD-10-CM) coding system. In 2017, injury visits included those with a reason for visit code related to injury and poisoning based on NCHS' Reason for Visit Classification or a diagnosis code related to injury and poisoning based on ICD-10-CM. "All injury visits" includes any listed reason for visit and diagnosis codes related to injury and poisoning. Injury visits do not include adverse effects and complication codes. Using this definition, injury visits represent $28.8 \%$ of all emergency department visits. For more details, see the 2017 National Hospital Ambulatory Medical Care Survey public-use data file documentation, available from: https://ftp.cdc.gov/pub/Health_Statistics/ NCHS/Dataset_Documentation/NHAMCS/doc17_ed-508.pdf.

${ }^{3}$ Population estimates by metropolitan statistical area (MSA) status are based on data from the 2017 National Health Interview Survey, compiled according to the Office of Management and Budget definitions of core-based statistical areas as of February 2013. More information about MSA definitions is available from: https://www.census.gov/programs-surveys/metro-micro.html. NOTE: Numbers may not add to totals because of rounding.

SOURCE: NCHS, National Hospital Ambulatory Medical Care Survey, 2017. 
Table 15. Injury visits to emergency departments, by race, age, and ethnicity: United States, 2017

\begin{tabular}{|c|c|c|c|}
\hline Patient characteristic & $\begin{array}{l}\text { Number of visits } \\
\text { (standard error) } \\
\text { in thousands }\end{array}$ & $\begin{array}{l}\text { Percent distribution } \\
\text { (standard error) }\end{array}$ & $\begin{array}{c}\text { Number of visits per } \\
100 \text { persons per year }{ }^{1} \\
\text { (standard error) }\end{array}$ \\
\hline All injury visits ${ }^{2}$ & $39,972(3,052)$ & $100.0 \ldots$ & $12.5(1.0)$ \\
\hline \multicolumn{4}{|c|}{ Race $^{3}$ and age group (years) } \\
\hline White & $28,938(2,419)$ & $72.4(1.9)$ & $11.8(1.0)$ \\
\hline Under 15 & $5,974(780)$ & $14.9(1.5)$ & $13.6(1.8)$ \\
\hline $15-24$ & $4,291(434)$ & $10.7(0.6)$ & $13.8(1.4)$ \\
\hline $25-44$ & $7,669(814)$ & $19.2(1.2)$ & $12.2(1.3)$ \\
\hline $45-64$ & $5,739(477)$ & $14.4(0.8)$ & $8.6(0.7)$ \\
\hline $65-74$ & $2,165(285)$ & $5.4(0.6)$ & $8.8(1.2)$ \\
\hline 75 and over & 3,099 (375) & $7.8(0.7)$ & $18.0(2.2)$ \\
\hline Black or African American & $9,508(993)$ & $23.8(1.8)$ & $22.6(2.4)$ \\
\hline Under 15 & $2,273(340)$ & $5.7(0.8)$ & $24.7(3.7)$ \\
\hline $15-24$ & $1,899(284)$ & $4.8(0.6)$ & $29.8(4.5)$ \\
\hline $25-44$ & $2,863(318)$ & $7.2(0.6)$ & $24.5(2.7)$ \\
\hline $45-64$ & $1,846(263)$ & $4.6(0.5)$ & $17.9(2.5)$ \\
\hline $65-74$ & *403 (137) & $1.0(0.3)$ & $13.9(4.7)$ \\
\hline 75 and over & * $\ldots$ & $0.6(0.2)$ & $13.1(4.5)$ \\
\hline Other ${ }^{4}$ & $1,527(282)$ & $3.8(0.7)$ & $4.7(0.9)$ \\
\hline \multicolumn{4}{|l|}{ Ethnicity ${ }^{3}$} \\
\hline Hispanic & $5,645(861)$ & $14.1(1.8)$ & $9.7(1.5)$ \\
\hline Not Hispanic & $34,327(2,661)$ & $85.9(1.8)$ & $13.1(1.0)$ \\
\hline White & $23,813(2,043)$ & $59.6(2.1)$ & $12.2(1.0)$ \\
\hline Black or African American & $9,085(951)$ & $22.7(1.7)$ & $23.1(2.4)$ \\
\hline Other ${ }^{4}$ & $1,429(278)$ & $3.6(0.7)$ & $5.1(1.0)$ \\
\hline
\end{tabular}

... Category not applicable.

* Estimate does not meet NCHS standards of reliability.

${ }^{1}$ Visit rates are based on the July 1, 2017, estimates of the U.S. civilian noninstitutional population as developed by the U.S. Census Bureau, Population Division.

${ }^{2}$ The definition of injury changed in 2016 due to the switch from the International Classification of Diseases, Ninth Revision, Clinical Modification (ICD-9-CM) coding system for diagnosis data to the International Classification of Diseases, 10th Revision, Clinical Modification (ICD-10-CM) coding system. In 2017, injury visits included those with a reason-for-visit code related to injury and poisoning based on the National Center for Health Statistics' (NCHS) Reason for Visit Classification or a diagnosis code related to injury and poisoning based on ICD-10-CM. "All injury visits" includes any listed reason for visit and diagnosis codes related to injury and poisoning. Injury visits do not include adverse effects and complication codes. Using this definition, injury visits represent $28.8 \%$ of all emergency department visits. For more details, see the 2017 National Hospital Ambulatory Medical Care Survey (NHAMCS) public-use data file documentation, available from: https://ftp.cdc.gov/pub/Health_Statistics/NCHS/Dataset_Documentation/NHAMCS/doc17_ed-508.pdf.

${ }^{3}$ The race groups white, black or African American, and other include persons of Hispanic and non-Hispanic origin. Persons of Hispanic origin may be of any race. For 2017, race data were missing for $15.0 \%$ of injury visits, and ethnicity data were missing for $19.2 \%$ of injury visits. NCHS uses model-based single imputation for NHAMCS race and ethnicity data. The race imputation is restricted to three categories (white, black, and other) based on research by an internal work group and on quality concerns with imputed estimates for race categories other than white and black. The imputation technique is detailed in the 2009 NHAMCS public-use data file documentation, available from: https://ftp.cdc.gov/pub/Health_Statistics/NCHS/Dataset_ Documentation/NHAMCS/doc09.pdf.

${ }^{4}$ Includes Asian, Native Hawaiian or Other Pacific Islander, American Indian or Alaska Native, and persons with more than one race.

NOTES: Numbers may not add to totals because of rounding. Visit estimates are not presented if they are based on fewer than 30 cases in the sample data, in which case only an asterisk is shown. Visit estimates based on 30 cases or more include an asterisk if the relative standard error of the estimate exceeds $30 \%$. Proportion estimates are not presented if they are unreliable based on the procedure specified in "National Center for Health Statistics Data Presentation Standards for Proportions" (https://www.cdc.gov/nchs/data/series/sr_02/sr02_175.pdf), in which case only an asterisk is shown.

SOURCE: NCHS, National Hospital Ambulatory Medical Care Survey, 2017. 
Table 16. Emergency department visits related to injury, poisoning, and adverse effect, by intent: United States, 2017

\begin{tabular}{lcr}
\hline \multicolumn{1}{c}{ Intent $^{1}$} & $\begin{array}{c}\text { Number of visits } \\
\text { (standard error) } \\
\text { in thousands }\end{array}$ & $\begin{array}{c}\text { Percent distribution } \\
\text { (standard error) }\end{array}$ \\
\hline $\begin{array}{l}\text { All injury visits related to injury, poisoning, } \\
\text { and adverse effect }{ }^{2}\end{array}$ & $43,193(3,238)$ & $100.0 \ldots$ \\
Unintentional & $29,442(2,244)$ & $68.2(1.2)$ \\
Self-harm & $479(118)$ & $1.1(0.2)$ \\
Assault & $1,684(212)$ & $3.9(0.4)$ \\
Legal intervention/war & $* \ldots$ & $\ldots$ \\
Undetermined or other ${ }^{3}$ & $1,261(199)$ & $2.9(0.4)$ \\
Blank cause & $10,279(917)$ & $23.8(1.1)$ \\
\hline
\end{tabular}

... Category not applicable.

* Estimate does not meet NCHS standards of reliability.

1 Based on the proposed International Classification of Diseases, 10th Revision, Clinical Modification (ICD-10-CM) external cause-of-injury matrix, available from: https://www.cdc.gov/ injury/wisqars/pdf/ICD-10-CM_External_Cause_Injury_Codes-a.pdf.

${ }^{2}$ The definition of injury changed in 2016 due to the switch from the International Classification of Diseases, Ninth Revision, Clinical Modification (ICD-9-CM) coding system for diagnosis data to the ICD-10-CM coding system. In 2017, injury visits included those with a reason-for-visit code related to injury and poisoning based on the National Center for Health Statistics' Reason for Visit Classification or a diagnosis code related to injury and poisoning based on ICD-10-CM. Using this definition, injury visits accounted for $31.1 \%$ (standard error $=0.8$ ) of all emergency department visits in 2017.

${ }^{3}$ Other includes certain diagnosis codes for injury visits not captured using the ICD-10-CM external-cause matrix. Common diagnoses in this group include medical and surgical complications, activity of person seeking health care (such as a heart attack while shoveling snow, which resulted from, or was contributed to, by the activity), and place of occurrence of external cause. For more details, see the 2017 National Hospital Ambulatory Medical Care Survey public-use data file documentation, available from: https://ftp.cdc.gov/pub/Health_ Statistics/NCHS/Dataset_Documentation/NHAMCS/doc17_ed-508.pdf.

NOTES: Numbers may not add to totals because of rounding. Visit estimates are not presented if they are based on fewer than 30 cases in the sample data, in which case only an asterisk is shown. Proportion estimates are not presented if they are unreliable based on the procedure specified in "National Center for Health Statistics Data Presentation Standards for Proportions" (https://www.cdc.gov/nchs/data/series/sr_02/sr02_175.pdf), in which case only an asterisk is shown.

SOURCE: NCHS, National Hospital Ambulatory Medical Care Survey, 2017. 
Table 17. Emergency department visits related to injury, poisoning, and adverse effect, by mechanism: United States, 2017

\begin{tabular}{|c|c|c|}
\hline Mechanism ${ }^{1}$ & $\begin{array}{l}\text { Number of visits } \\
\text { (standard error) } \\
\text { in thousands }\end{array}$ & $\begin{array}{l}\text { Percent distribution } \\
\text { (standard error) }\end{array}$ \\
\hline $\begin{array}{l}\text { All injury visits related to injury } \\
\text { and adverse effect }{ }^{2}\end{array}$ & $43,193(3,238)$ & $100.0 \ldots$ \\
\hline Cut or pierce & $2,263(269)$ & $5.2(0.5)$ \\
\hline Drowning or submersion & $* \ldots$ & * $\ldots$ \\
\hline Fall & $10,511(919)$ & $24.3(1.0)$ \\
\hline Fire or burn & $460(91)$ & $1.1(0.2)$ \\
\hline Fire or flame & * $\ldots$ & $0.4(0.2)$ \\
\hline Hot object or substance & $266(62)$ & $0.6(0.1)$ \\
\hline Firearm & * $\ldots$ & $0.3(0.1)$ \\
\hline Machinery & $260(60)$ & $0.6(0.1)$ \\
\hline All transportation & $5,176(513)$ & $12.0(0.7)$ \\
\hline Motor vehicle-traffic & $3,448(356)$ & $8.0(0.5)$ \\
\hline Motor vehicle-nontraffic & $312(61)$ & $0.7(0.1)$ \\
\hline Pedal cyclist, other & *... & $0.5(0.1)$ \\
\hline Pedestrian, other & * $\ldots$ & $0.1(0.1)$ \\
\hline Other land transport & $1,117(222)$ & $2.6(0.5)$ \\
\hline Other transport & * $\ldots$ & $0.1(0.0)$ \\
\hline Natural or environmental ${ }^{3}$ & $1,590(217)$ & $3.7(0.4)$ \\
\hline Overexertion & $1,635(182)$ & $3.8(0.3)$ \\
\hline Struck by or against & $5,317(473)$ & $12.3(0.5)$ \\
\hline Other specified ${ }^{4}$ & $952(129)$ & $2.2(0.3)$ \\
\hline Unspecified or other ${ }^{5}$ & $4,632(422)$ & $10.7(0.7)$ \\
\hline Blank cause & $10,279(917)$ & $23.8(1.1)$ \\
\hline
\end{tabular}

... Category not applicable.

* Estimate does not meet NCHS standards of reliability.

'Based on the proposed International Classification of Diseases, 10th Revision, Clinical Modification (ICD-10-CM) external cause-of-injury matrix, available from: https://www.cdc.gov/injury/ wisqars/pdf/ICD-10-CM_External_Cause_Injury_Codes-a.pdf.

${ }^{2}$ The definition of injury changed in 2016 due to the switch from the International Classification of Diseases, Ninth Revision, Clinical Modification (ICD-9-CM) coding system for diagnosis data to the ICD-10-CM coding system. In 2017, injury visits included those with a reason-for-visit code related to injury and poisoning based on the National Center for Health Statistics' Reason for Visit Classification or a diagnosis code related to injury and poisoning based on ICD-10-CM. Using this definition, injury visits accounted for $31.1 \%$ (standard error $=0.8$ ) of all emergency department visits in 2017

${ }^{3}$ Includes bites and stings (venomous and nonvenomous), natural or environmental, and other

${ }_{4}^{4}$ Includes child or adult abuse, foreign body, classifiable and not elsewhere classifiable.

${ }^{5}$ Other includes certain diagnosis codes for injury visits not captured using the ICD-10-CM external-cause matrix. Common diagnoses in this group include medical and surgical complications, activity of person seeking health care (such as a heart attack while shoveling snow, which resulted from, or was contributed to, by the activity), and place of occurrence of external cause. For more details, see the 2017 National Hospital Ambulatory Medical Care Survey public-use data file documentation, available from: https:/ftp.cdc.gov/pub/Health_Statistics/ NCHS/Dataset_Documentation/NHAMCS/doc17_ed-508.pdf.

NOTES: Numbers may not add to totals because of rounding. Visit estimates are not presented if they are based on fewer than 30 cases in the sample data, in which case only an asterisk is shown. Proportion estimates are not presented if they are unreliable based on the procedure specified in "National Center for Health Statistics Data Presentation Standards for Proportions" (https://www.cdc.gov/nchs/data/series/sr_02/sr02_175.pdf), in which case only an asterisk is shown.

SOURCE: NCHS, National Hospital Ambulatory Medical Care Survey, 2017. 
Table 18. Selected diagnostic and screening services ordered or provided at emergency department visits: United States, 2017

\begin{tabular}{|c|c|c|}
\hline Diagnostic and screening services ordered or provided & $\begin{array}{c}\text { Number of visits }{ }^{1} \\
\text { (standard error) } \\
\text { in thousands }\end{array}$ & $\begin{array}{l}\text { Percent distribution } \\
\text { (standard error) }\end{array}$ \\
\hline All visits & $138,977(10,277)$ & $\ldots \ldots$ \\
\hline One or more diagnostic or screening service listed & $102,231(7,941)$ & $73.6(1.1)$ \\
\hline None & $35,159(2,876)$ & $25.3(1.2)$ \\
\hline Blank & $1,587(368)$ & $1.1(0.3)$ \\
\hline \multicolumn{3}{|l|}{ Blood tests } \\
\hline Complete blood count & $53,751(4,572)$ & $38.7(1.7)$ \\
\hline Creatinine or renal function panel & $5,292(1,529)$ & $3.8(1.1)$ \\
\hline Glucose, serum & $8,494(1,770)$ & $6.1(1.2)$ \\
\hline Electrolytes & $2,598(743)$ & $1.9(0.5)$ \\
\hline Prothrombin time (PT/PTT/INR) ${ }^{2}$ & $10,971(1,337)$ & $7.9(0.8)$ \\
\hline Liver enzymes or hepatic function panel & $4,841(792)$ & $3.5(0.5)$ \\
\hline Cardiac enzymes & $6,790(1,151)$ & $4.9(0.8)$ \\
\hline Comprehensive metabolic panel & $40,122(3,746)$ & $28.9(1.6)$ \\
\hline Blood culture & $6,523(811)$ & $4.7(0.5)$ \\
\hline Brain natriuretic peptide & $4,102(716)$ & $3.0(0.4)$ \\
\hline D-dimer & $2,851(394)$ & $2.1(0.2)$ \\
\hline Arterial blood gases & *2,883 (960) & $2.1(0.7)$ \\
\hline Blood alcohol concentration & $2,783(454)$ & $2.0(0.3)$ \\
\hline Basic metabolic panel & $12,366(1,751)$ & $8.9(1.0)$ \\
\hline Lactate & $3,087(428)$ & $2.2(0.3)$ \\
\hline Other blood test & $31,196(3,117)$ & $22.4(1.4)$ \\
\hline Any blood test listed & $61,934(4,887)$ & $44.6(1.3)$ \\
\hline \multicolumn{3}{|l|}{ Imaging } \\
\hline X-ray & $48,909(3,750)$ & $35.2(1.0)$ \\
\hline Computed tomography (CT) scan & $24,687(2,268)$ & $17.8(0.9)$ \\
\hline Abdomen or pelvis & $10,436(1,072)$ & $7.5(0.5)$ \\
\hline Chest & $3,324(454)$ & $2.4(0.3)$ \\
\hline Head & $10,738(1,073)$ & $7.7(0.5)$ \\
\hline Other & $4,310(477)$ & $3.1(0.3)$ \\
\hline Intravenous (IV) contrast with CT & $7,240(832)$ & $5.2(0.4)$ \\
\hline Ultrasound & $7,773(1,001)$ & $5.6(0.5)$ \\
\hline Magnetic resonance imaging (MRI) scan & $1,442(233)$ & $1.0(0.1)$ \\
\hline IV contrast with MRI & * $\ldots$ & $0.1(0.0)$ \\
\hline Other imaging & $1,372(238)$ & $1.0(0.2)$ \\
\hline Any imaging & $69,036(5,435)$ & $49.7(1.2)$ \\
\hline \multicolumn{3}{|l|}{ Examinations and tests } \\
\hline Cardiac monitor & $11,884(1,344)$ & $8.6(0.8)$ \\
\hline Urinalysis or urine dipstick & $36,289(3,259)$ & $26.1(1.1)$ \\
\hline Electrocardiogram & $27,928(2,476)$ & $20.1(1.1)$ \\
\hline Urine culture & $14,311(1,402)$ & $10.3(0.7)$ \\
\hline Pregnancy/HCG test ${ }^{3}$ & $13,071(1,371)$ & $9.4(0.6)$ \\
\hline Toxicology screen & $6,781(889)$ & $4.9(0.5)$ \\
\hline Influenza test & $5,722(1,103)$ & $4.1(0.7)$ \\
\hline Throat culture & $3,040(725)$ & $2.2(0.5)$ \\
\hline Wound culture & $821(184)$ & $0.6(0.1)$ \\
\hline Other culture & $1,897(417)$ & $1.4(0.3)$ \\
\hline HIV test & $692(129)$ & $0.5(0.1)$ \\
\hline Other test or service & $22,175(3,141)$ & $16.0(1.8)$ \\
\hline
\end{tabular}

... Category not applicable.

*Estimate does not meet NCHS standards of reliability.

${ }^{1}$ Total exceeds "All visits" and percentage exceeds $100 \%$ because more than one service may be reported per visit.

${ }^{2} \mathrm{PT}$ is prothrombin time, PTT is partial thromboplastin time, and INR is international normalized ratio.

${ }^{3} \mathrm{HCG}$ is human chorionic gonadotropin.

NOTES: Visit estimates are not presented if they are based on fewer than 30 cases in the sample data, in which case only an asterisk is shown. Visit estimates based on 30 cases or more include an asterisk if the relative standard error of the estimate exceeds $30 \%$. Proportion estimates are not presented if they are unreliable based on the procedure specified in "National Center for Health Statistics Data Presentation Standards for Proportions" (https://www.cdc.gov/nchs/data/series/sr_02/sr02 175.pdf), in which case only an asterisk is shown.

SOURCE: NCHS, National Hospital Ambulatory Medical Care Survey, 2017. 
Table 19. Selected procedures at emergency department visits: United States, 2017

\begin{tabular}{|c|c|c|}
\hline Procedure performed & $\begin{array}{l}\text { Number of visits }{ }^{1} \\
\text { (standard error) } \\
\text { in thousands }\end{array}$ & $\begin{array}{l}\text { Percent distribution } \\
\text { (standard error) }\end{array}$ \\
\hline All visits & $138,977(10,277)$ & $\ldots \ldots$ \\
\hline One or more procedure listed & $60,102(5,090)$ & $43.2(1.6)$ \\
\hline None $^{1}$ & $75,227(6,082)$ & $54.1(1.8)$ \\
\hline Blank $^{2}$ & $3,648(1,043)$ & $2.6(0.7)$ \\
\hline Intravenous fluids & $35,929(3,498)$ & $25.9(1.4)$ \\
\hline Cast, splint, wrap & 6,832 (563) & $4.9(0.3)$ \\
\hline Suturing or staples & 3,267 (373) & $2.4(0.2)$ \\
\hline Incision and drainage & 1,369 (169) & $1.0(0.1)$ \\
\hline Nebulizer therapy & $4,125(565)$ & $3.0(0.4)$ \\
\hline Bladder catheter & 2,415 (474) & $1.7(0.3)$ \\
\hline Pelvic examination & 1,876 (346) & $1.3(0.2)$ \\
\hline Central line & *1,356 (762) & $1.0(0.5)$ \\
\hline Cardiopulmonary resuscitation (CPR) & ${ }^{*} \ldots$ & $0.1(0.0)$ \\
\hline Endotracheal intubation & $229(64)$ & $0.2(0.0)$ \\
\hline Skin adhesives & $1,398(240)$ & $1.0(0.2)$ \\
\hline BiPAP or CPAP ${ }^{3}$ & *758 (327) & $0.5(0.2)$ \\
\hline Lumbar puncture & *422 (127) & $0.3(0.1)$ \\
\hline Other ${ }^{4}$ & $11,854(1,550)$ & $8.5(1.0)$ \\
\hline
\end{tabular}

... Category not applicable.

* Estimate does not meet NCHS standards of reliability.

0.0 Quantity more than zero but less than 0.05 .

${ }^{1}$ The "None" checkbox was marked on the Patient Record Form (PRF).

${ }^{2}$ No checkboxes were marked on PRF.

${ }^{3}$ BiPAP is variable or bi-level positive airway pressure, and CPAP is continuous positive airway pressure.

${ }^{4}$ Includes all other procedures not listed above.

NOTES: Visit estimates are not presented if they are based on fewer than 30 cases in the sample data, in which case only an asterisk is shown. Visit estimates based on 30 cases or more include an asterisk if the relative standard error of the estimate exceeds $30 \%$. Proportion estimates are not presented if they are unreliable based on the procedure specified in "National Center for Health Statistics Data Presentation Standards for Proportions" (https://www.cdc.gov/nchs/data/series/sr_02/sr02_175.pdf), in which case only an asterisk is shown.

SOURCE: NCHS, National Hospital Ambulatory Medical Care Survey, 2017. 
Table 20. Medication therapy and number of medications mentioned at emergency department visits: United States, 2017

\begin{tabular}{|c|c|c|}
\hline Medication therapy ${ }^{1}$ & $\begin{array}{l}\text { Number of visits } \\
\text { (standard error) } \\
\text { in thousands }\end{array}$ & $\begin{array}{l}\text { Percent distribution } \\
\text { (standard error) }\end{array}$ \\
\hline $\begin{array}{l}\text { Visits with mention of medication }{ }^{2} \\
\text { Visits without mention of medication }\end{array}$ & $\begin{array}{r}112,767(8,723) \\
26,210(2,530)\end{array}$ & $\begin{array}{l}81.1(1.3) \\
18.9(1.3)\end{array}$ \\
\hline \multicolumn{3}{|c|}{$\begin{array}{l}\text { Number of medications provided } \\
\text { or prescribed } \\
\text { or }\end{array}$} \\
\hline 0 medications & $26,210(2,530)$ & $18.9(1.3)$ \\
\hline 1 medication & $29,535(2,550)$ & $21.3(0.7)$ \\
\hline 2 medications & $26,681(2,109)$ & $19.2(0.7)$ \\
\hline 3 medications & $19,296(1,561)$ & $13.9(0.4)$ \\
\hline 4 medications & $13,068(1,242)$ & $9.4(0.5)$ \\
\hline 5 medications & $8,682(866)$ & $6.2(0.3)$ \\
\hline 10 medications & 815 (150) & $0.6(0.1)$ \\
\hline 11 medications & $457(91)$ & $0.3(0.1)$ \\
\hline 12 medications & $622(117)$ & $0.4(0.1)$ \\
\hline 13 medications or more & 1,706 (355) & $1.2(0.3)$ \\
\hline
\end{tabular}

... Category not applicable.

${ }^{1}$ Includes prescription drugs, over-the-counter preparations, immunizations, and desensitizing agents.

${ }^{2}$ Visits at which one or more drugs were given in the emergency department (ED) or prescribed at discharge (up to 30 per visit); also defined as drug visit.

${ }^{3}$ Drug mentions totaled $368,454,000$ at ED visits in 2017. The average drug mention rate was 2.7 drug mentions per ED visit. For visits with at least one drug mention, the average drug visit rate was 3.3 drugs per visit.

NOTE: Numbers may not add to totals because of rounding.

SOURCE: NCHS, National Hospital Ambulatory Medical Care Survey, 2017. 
Table 21. Twenty most frequently mentioned drugs at emergency department visits, by therapeutic drug category: United States, 2017

\begin{tabular}{|c|c|c|}
\hline Drug category $^{1}$ & $\begin{array}{c}\text { Number of occurrences } \\
\text { (standard error) } \\
\text { in thousands }\end{array}$ & $\begin{array}{l}\text { Percent of drug mentions }{ }^{2} \\
\text { (standard error) }\end{array}$ \\
\hline Analgesics $^{3}$ & $98,405(8,190)$ & $26.7(0.6)$ \\
\hline Antiemetic or antivertigo agents & $39,690(3,386)$ & $10.8(0.3)$ \\
\hline Minerals and electrolytes & $36,666(4,121)$ & $10.0(0.7)$ \\
\hline Miscellaneous respiratory agents & $29,290(3,304)$ & $7.9(0.6)$ \\
\hline Anxiolytics, sedatives, and hypnotics & $15,391(1,311)$ & $4.2(0.2)$ \\
\hline Bronchodilators & $14,341(1,183)$ & $3.9(0.2)$ \\
\hline Adrenal cortical steroids & $12,716(1,322)$ & $3.5(0.2)$ \\
\hline Antihistamines & $11,565(1,056)$ & $3.1(0.1)$ \\
\hline Anticonvulsants & $10,530(1,040)$ & $2.9(0.2)$ \\
\hline Cephalosporins & $10,329(938)$ & $2.8(0.2)$ \\
\hline Penicillins & $9,150(989)$ & $2.5(0.2)$ \\
\hline Dermatological agents & $8,400(832)$ & $2.3(0.1)$ \\
\hline Muscle relaxants & $6,683(819)$ & $1.8(0.2)$ \\
\hline Local injectable anesthetics & $6,672(661)$ & $1.8(0.1)$ \\
\hline Antiarrhythmic agents & 6,627 (629) & $1.8(0.1)$ \\
\hline Antiparkinson agents & $6,129(566)$ & $1.7(0.1)$ \\
\hline Laxatives & $5,363(821)$ & $1.5(0.2)$ \\
\hline Antiplatelet agents & $5,122(574)$ & $1.4(0.1)$ \\
\hline Radiocontrast agents & $5,057(676)$ & $1.4(0.1)$ \\
\hline Macrolide derivatives & $4,921(511)$ & $1.3(0.1)$ \\
\hline
\end{tabular}

${ }^{1}$ Based on Cerner Multum second-level therapeutic drug category, available from: https://www.cerner.com/solutions/drug-database.

2Based on an estimated 368,454,000 drug mentions at emergency department (ED) visits in 2017. Drug mentions are medications given in EDs or prescribed at discharge.

${ }^{3}$ Includes narcotics (10.6\%), nonsteroidal anti-inflammatory drugs (10.1\%), and other analgesics, including salicylates, analgesic combinations, antimigraine agents, Cox-2 inhibitors, and miscellaneous analgesics (6.0\%).

SOURCE: NCHS, National Hospital Ambulatory Medical Care Survey, 2017. 
Table 22. Twenty most frequently mentioned drugs at emergency department visits: United States, 2017

Percent of drug mentions (standard error)

\begin{tabular}{|c|c|c|c|c|c|c|c|c|}
\hline Drug name ${ }^{1}$ & $\begin{array}{l}\text { Number of drug } \\
\text { mentions } \\
\text { (standard error) } \\
\text { in thousands }\end{array}$ & $\begin{array}{c}\text { Percent } \\
\text { distribution } \\
\text { (standard error) }\end{array}$ & Total & $\begin{array}{l}\text { Given in } \\
\text { emergency } \\
\text { department }\end{array}$ & $\begin{array}{l}\text { Prescribed } \\
\text { at discharge }\end{array}$ & $\begin{array}{l}\text { Both given in } \\
\text { emergency } \\
\text { department } \\
\text { and prescribed } \\
\text { at discharge }\end{array}$ & Unknown ${ }^{2}$ & Therapeutic drug category ${ }^{3}$ \\
\hline & & & & \multicolumn{4}{|c|}{ Percent of mention (standard error) } & \\
\hline All drug mentions & $368,454(30,024)$ & $100.0(0.0)$ & 100.0 & $58.1(2.0)$ & $32.3(2.1)$ & $8.9(0.9)$ & $0.7(0.3)$ & $\ldots$ \\
\hline Sodium chloride & $29,262(3,306)$ & $7.9(0.6)$ & 100.0 & $98.2(0.4)$ & $1.2(0.3)$ & $0.4(0.2)$ & $0.2(0.1)$ & $\begin{array}{l}\text { Minerals and electrolytes, } \\
\text { miscellaneous respiratory agents }\end{array}$ \\
\hline Ondansetron & $22,445(2,035)$ & $6.1(0.2)$ & 100.0 & $69.5(2.0)$ & $12.4(1.1)$ & $17.6(1.9)$ & $0.5(0.3)$ & Antiemetic or antivertigo agents \\
\hline Ibuprofen & $19,637(1,698)$ & $5.3(0.3)$ & 100.0 & $34.3(2.7)$ & $49.4(2.8)$ & $16.2(1.8)$ & $0.2(0.1)$ & Analgesics \\
\hline Acetaminophen & $16,519(1,485)$ & $4.5(0.3)$ & 100.0 & $53.5(3.6)$ & $33.5(3.6)$ & $12.4(1.9)$ & $0.7(0.3)$ & Analgesics \\
\hline Ketorolac & $11,863(1,370)$ & $3.2(0.2)$ & 100.0 & **89.2 (3.3) & $4.6(1.3)$ & * $\ldots$ & * ... & Analgesics \\
\hline Acetaminophen-hydrocodone & $9,748(1,159)$ & $2.6(0.2)$ & 100.0 & $35.9(3.3)$ & $48.8(2.8)$ & $15.0(1.8)$ & * $\ldots$ & Analgesics \\
\hline Morphine & $8,143(924)$ & $2.2(0.1)$ & 100.0 & $97.8(0.8)$ & $1.0(0.3)$ & $0.8(0.5)$ & * $\ldots$ & Analgesics \\
\hline Albuterol & $7,867(699)$ & $2.1(0.1)$ & 100.0 & $37.4(2.9)$ & $47.5(3.6)$ & $14.5(2.3)$ & $0.6(0.4)$ & Bronchodilators \\
\hline Diphenhydramine & $5,851(533)$ & $1.6(0.1)$ & 100.0 & $67.8(3.6)$ & $20.0(2.8)$ & $12.0(2.0)$ & * $\ldots$ & $\begin{array}{l}\text { Antiemetic or antivertigo agents, } \\
\text { antihistamines, antiparkinson } \\
\text { agents, anxiolytics, sedatives, } \\
\text { hypnotics }\end{array}$ \\
\hline Prednisone & $5,120(621)$ & $1.4(0.1)$ & 100.0 & $17.9(2.6)$ & $66.3(4.0)$ & $15.5(2.8)$ & * $\ldots$ & Adrenal cortical steroids \\
\hline Hydromorphone & $4,926(618)$ & $1.3(0.1)$ & 100.0 & $97.3(0.8)$ & $1.9(0.7)$ & ${ }^{*} \ldots$ & ${ }^{*} \ldots$ & $\begin{array}{l}\text { Analgesics } \\
\text { Antiarrhythmic agents, local }\end{array}$ \\
\hline Lidocaine & $4,844(466)$ & $1.3(0.1)$ & 100.0 & $90.1(1.9)$ & $7.8(1.7)$ & $2.0(0.6)$ & ${ }^{*} \ldots$ & injectable anesthetics \\
\hline Aspirin & $4,541(480)$ & $1.2(0.1)$ & 100.0 & $74.2(4.8)$ & $21.9(4.6)$ & $3.0(0.8)$ & $1.0(0.8)$ & Analgesics, antiplatelet agents \\
\hline Azithromycin & $4,527(473)$ & $1.2(0.1)$ & 100.0 & $34.2(2.9)$ & $54.0(3.8)$ & $11.3(2.5)$ & ${ }^{*} \ldots$ & Macrolide derivatives \\
\hline Ceftriaxone & $4,446(450)$ & $1.2(0.1)$ & 100.0 & $97.7(0.6)$ & $1.2(0.5)$ & $1.0(0.4)$ & * $\ldots$ & Cephalosporins \\
\hline Cephalexin & $4,211(456)$ & $1.1(0.1)$ & 100.0 & $12.1(2.3)$ & $76.2(3.4)$ & $11.7(2.0)$ & * $\ldots$ & Cephalosporins \\
\hline Amoxicillin & $4,193(493)$ & $1.1(0.1)$ & 100.0 & * ... & $67.8(4.3)$ & $20.7(3.8)$ & * $\ldots$ & Penicillins \\
\hline Lorazepam & $4,045(422)$ & $1.1(0.1)$ & 100.0 & $79.4(2.9)$ & $14.2(3.2)$ & $5.9(1.6)$ & ${ }^{*} \ldots$ & $\begin{array}{l}\text { Anticonvulsants, antiemetic or } \\
\text { antivertigo agents, anxiolytics, } \\
\text { sedatives, hypnotics }\end{array}$ \\
\hline Acetaminophen-oxycodone & $4,002(659)$ & $1.1(0.2)$ & 100.0 & $41.0(4.8)$ & $38.7(5.5)$ & $20.0(3.1)$ & * $\ldots$ & Analgesics \\
\hline Tramadol & $3,908(604)$ & $1.1(0.1)$ & 100.0 & $19.6(3.5)$ & $68.3(3.6)$ & $11.8(2.5)$ & ${ }^{*} \ldots$ & Analgesics \\
\hline All other & $188,358(16,365)$ & $51.1(1.1)$ & 100.0 & $52.6(2.6)$ & $38.3(2.9)$ & $7.9(1.1)$ & $1.1(0.5)$ & $\ldots$ \\
\hline
\end{tabular}

0.0 Quantity more than zero but less than 0.05

ate meets NCHS standards of reliability, but its complement does not

not meet NCHS standards of reliability.

Based on Cerner Multum terminology, the drug name reflects the active ingredients of a drug mention.

作

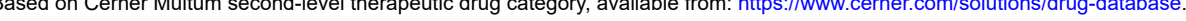

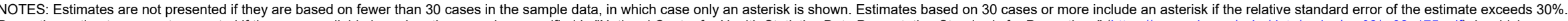
only an asteristimates are not

SOURCE: NCHS, National Hospital Ambulatory Medical Care Survey, 2017. 
Table 23. Providers seen at emergency department visits: United States, 2017

\begin{tabular}{lrr}
\hline \multicolumn{1}{c}{ Type of provider } & $\begin{array}{c}\text { Number of visits } \\
\text { (standard error) } \\
\text { in thousands }\end{array}$ & $\begin{array}{c}\text { Percent distribution } \\
\text { (standard error) }\end{array}$ \\
\hline All visits & $138,977(10,277)$ & $\ldots$ \\
Any physician & $119,581(8,754)$ & $\ldots 6.0(1.7)$ \\
Emergency department attending physician & $116,305(8,603)$ & $83.7(2.0)$ \\
Emergency department resident or intern & $15,679(2,603)$ & $11.3(1.7)$ \\
Consulting physician & $13,007(1,693)$ & $9.4(1.1)$ \\
Registered nurse or licensed practical nurse & $128,277(9,994)$ & $92.3(1.6)$ \\
Any physician seen & $110,457(8,512)$ & $79.5(2.0)$ \\
Physician not seen & $17,820(2,862)$ & $12.8(1.7)$ \\
Nurse practitioner & $16,235(2,637)$ & $11.7(1.6)$ \\
$\quad$ Any physician seen & $7,301(1,601)$ & $5.3(1.1)$ \\
Physician not seen & $8,934(1,901)$ & $6.4(1.2)$ \\
Physician assistant & $17,775(2,582)$ & $12.8(1.6)$ \\
Any physician seen & $10,680(1,865)$ & $7.7(1.3)$ \\
Physician not seen & $7,095(1,462)$ & $5.1(0.9)$ \\
Emergency medical technician & $7,207(1,091)$ & $5.2(0.7)$ \\
Mental health provider & $2,324(335)$ & $1.7(0.2)$ \\
Other & $42,913(5,215)$ & $30.9(2.9)$ \\
Blank & $211(55)$ & $0.2(0.0)$ \\
\hline
\end{tabular}

... Category not applicable.

"Total exceeds "All visits" and percentage exceeds $100 \%$ because more than one provider may be reported per visit.

SOURCE: NCHS, National Hospital Ambulatory Medical Care Survey, 2017. 
Table 24. Disposition of emergency department visits: United States, 2017

\begin{tabular}{|c|c|c|}
\hline Disposition & $\begin{array}{l}\text { Number of visits }{ }^{1} \\
\text { (standard error) } \\
\text { in thousands }\end{array}$ & $\begin{array}{l}\text { Percent of visits } \\
\text { (standard error) }\end{array}$ \\
\hline \multicolumn{3}{|l|}{ Admitted, transferred, or died } \\
\hline Admit to this hospital & $14,503(1,905)$ & $10.4(1.0)$ \\
\hline Critical care unit & $1,995(441)$ & $1.4(0.3)$ \\
\hline Mental health or detoxification unit & $594(129)$ & $0.4(0.1)$ \\
\hline Cardiac catheterization laboratory & $249(66)$ & $0.2(0.0)$ \\
\hline Other bed or unit & $6,966(907)$ & $5.0(0.5)$ \\
\hline Unknown or blank & $2,742(656)$ & $2.0(0.4)$ \\
\hline Admit to observation unit & $3,929(931)$ & $2.8(0.6)$ \\
\hline Then hospitalized & $1,318(375)$ & $0.9(0.3)$ \\
\hline Died in emergency department ${ }^{2}$ & * $\ldots$ & $0.2(0.0)$ \\
\hline \multicolumn{3}{|l|}{ Outpatient follow-up } \\
\hline Return or refer to physician or clinic for follow-up & $95,775(7,336)$ & $68.9(1.9)$ \\
\hline No follow-up planned & $13,000(1,870)$ & $9.4(1.2)$ \\
\hline \multicolumn{3}{|l|}{ Left prior to completing visit } \\
\hline Left without being seen & $1,578(245)$ & $1.1(0.2)$ \\
\hline Left before treatment complete & $968(221)$ & $0.7(0.1)$ \\
\hline Left against medical advice & $1,034(174)$ & $0.7(0.1)$ \\
\hline Other & $4,753(1,413)$ & $3.4(1.0)$ \\
\hline Blank & 885 (219) & $0.6(0.2)$ \\
\hline
\end{tabular}

... Category not applicable.

0.0 Quantity more than zero, but less than 0.05 .

* Estimate does not meet NCHS standards of reliability.

${ }^{1}$ Total exceeds "All visits" and percentage of visits exceeds $100 \%$ because more than one disposition may be reported per visit.

Includes "Dead on arrival."

NOTES: Visit estimates are not presented if they are based on fewer than 30 cases in the sample data, in which case only an asterisk is shown. Proportion estimates are not presented if they are unreliable based on the procedure specified in "National Center for Health Statistics Data Presentation Standards for Proportions" (https://www.cdc.gov/nchs/data/series/sr_02/sr02_175.pdf), in which case only an asterisk is shown.

SOURCE: NCHS, National Hospital Ambulatory Medical Care Survey, 2017. 
Table 25. Emergency department visits resulting in hospital admission, by selected patient and visit characteristics: United States, 2017

\begin{tabular}{|c|c|c|c|}
\hline Selected characteristic & $\begin{array}{l}\text { Number of visits } \\
\text { (standard error) } \\
\text { in thousands }\end{array}$ & $\begin{array}{l}\text { Percent distribution } \\
\text { (standard error) }\end{array}$ & $\begin{array}{l}\text { Admissions as } \\
\text { percent of visits } \\
\text { (standard error) }\end{array}$ \\
\hline All admissions & $14,503(1,905)$ & $100.0 \ldots$ & $10.4(1.0)$ \\
\hline \multicolumn{4}{|l|}{ Age (years) } \\
\hline Under 15 & *1,283 (532) & * $\ldots$ & * $\ldots$ \\
\hline $15-24$ & $1,126(252)$ & $7.8(1.5)$ & $5.6(1.0)$ \\
\hline $25-44$ & $2,154(356)$ & $14.9(1.7)$ & $5.6(0.8)$ \\
\hline $45-64$ & 3,941 (539) & $27.2(1.9)$ & $13.2(1.5)$ \\
\hline $65-74$ & $2,382(371)$ & $16.4(1.6)$ & $23.1(2.2)$ \\
\hline 75 and over & $3,617(580)$ & $24.9(2.2)$ & $30.0(2.9)$ \\
\hline \multicolumn{4}{|l|}{ Residence } \\
\hline Private & $12,800(1,704)$ & $88.3(1.4)$ & $9.7(0.9)$ \\
\hline Nursing home & 815 (178) & $5.6(0.9)$ & $37.8(4.6)$ \\
\hline Homeless & $184(51)$ & $1.3(0.4)$ & $18.6(4.0)$ \\
\hline Other & $316(76)$ & $2.2(0.5)$ & $17.7(3.9)$ \\
\hline Unknown or blank & 387 (106) & $2.7(0.7)$ & $15.5(3.2)$ \\
\hline \multicolumn{4}{|l|}{ Expected source of payment ${ }^{1}$} \\
\hline Private insurance & $5,359(815)$ & $36.9(2.6)$ & $12.4(1.4)$ \\
\hline Medicare & $6,304(958)$ & $43.5(3.5)$ & $24.6(2.2)$ \\
\hline $\begin{array}{l}\text { Medicaid or } \mathrm{CHIP}^{2} \text {, or other state-bas } \\
\text { program }\end{array}$ & $4,101(630)$ & $28.3(3.0)$ & $7.3(0.8)$ \\
\hline No insurance ${ }^{3}$ & $476(99)$ & $3.3(0.6)$ & $4.3(0.7)$ \\
\hline \multicolumn{4}{|l|}{ Mode of arrival } \\
\hline Ambulance & $5,659(777)$ & $39.0(2.2)$ & $28.1(2.3)$ \\
\hline Other & $8,844(1,240)$ & $61.0(2.2)$ & $7.4(0.8)$ \\
\hline \multicolumn{4}{|l|}{ Triage category } \\
\hline Immediate or emergent ${ }^{4}$ & $4,464(944)$ & $30.8(3.6)$ & $29.8(4.0)$ \\
\hline Other & $10,039(1,172)$ & $69.2(3.6)$ & $8.1(0.7)$ \\
\hline \multicolumn{4}{|c|}{$\begin{array}{l}\text { Patient seen in this emergency department } \\
\text { during the last } 72 \text { hours }\end{array}$} \\
\hline Yes & $544(117)$ & $3.8(0.7)$ & $12.5(2.7)$ \\
\hline No, unknown, or blank & $13,959(1,847)$ & $96.2(0.7)$ & $10.4(1.0)$ \\
\hline \multicolumn{4}{|l|}{ Hospital discharge status } \\
\hline Alive & $13,502(1,827)$ & $93.1(1.8)$ & $\ldots \ldots$ \\
\hline Home or residence & $10,912(1,501)$ & $80.8(1.4)$ & $\ldots \ldots$ \\
\hline Return or transfer to nursing home & $1,089(214)$ & $8.1(1.1)$ & $\ldots \ldots$ \\
\hline Transfer to another facility & $1,112(200)$ & $8.2(1.0)$ & $\ldots \ldots$ \\
\hline Other & * $\ldots$ & $1.0(0.2)$ & $\ldots \ldots$ \\
\hline Unknown or blank & $257(70)$ & $1.9(0.5)$ & $\ldots \cdots$ \\
\hline Died & $267(79)$ & $1.8(0.5)$ & $\cdots \cdots$ \\
\hline Unknown or blank & *734 (253) & * $\ldots$ & $\ldots \ldots$ \\
\hline
\end{tabular}

*.. Category not applicable.

* Estimate does not meet NCHS standards of reliability.

${ }^{1}$ Total exceeds "All visits" and percentage exceeds $100 \%$ because more than one source of payment may be reported per visit. Workers' compensation, other, and unknown sources of payment are not included in this table but account for $8.3 \%$ (weighted) of expected sources of payment.

${ }^{2}$ Children's Health Insurance Program.

${ }^{3}$ Defined as having only self-pay, no charge, or charity as payment sources. The individual self-pay and no charge or charity categories are not mutually exclusive.

${ }^{4}$ Defined as needing to be seen within $1-14$ minutes.

NOTES: Numbers may not add to totals because of rounding. Visit estimates are not presented if they are based on fewer than 30 cases in the sample data, in which case only an asterisk is shown. Visit estimates based on 30 cases or more include an asterisk if the relative standard error of the estimate exceeds $30 \%$. Proportion estimates are not presented if they are unreliable based on the procedure specified in "National Center for Health Statistics Data Presentation Standards for Proportions" (https://www.cdc.gov/nchs/data/series/sr_02/sr02_175.pdf), in which case only an asterisk is shown.

SOURCE: NCHS, National Hospital Ambulatory Medical Care Survey, 2017. 
Table 26. Principal hospital discharge diagnoses for patients admitted through the emergency department, by major disease category: United States, 2017

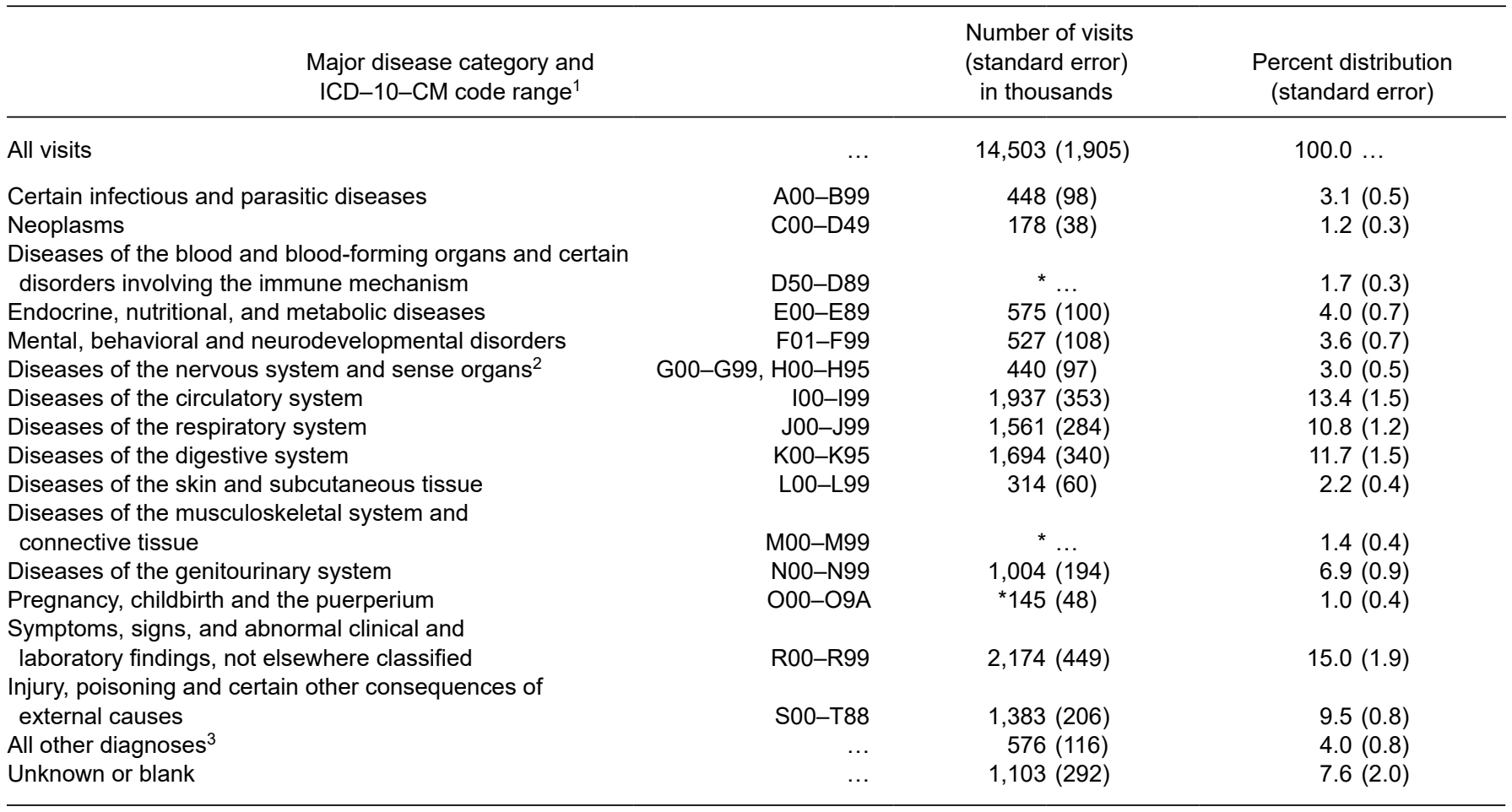

... Category not applicable.

* Estimate does not meet NCHS standards of reliability.

${ }^{1}$ Based on International Classification of Diseases, 10th Revision, Clinical Modification (ICD-10-CM). However, certain codes have been combined in this table to better describe the utilization of ambulatory care services.

${ }^{2}$ Sense organs include eye, adnexa, ear, and mastoid process.

Includes certain conditions originating in the perinatal period (P00-P96); congenital malformations, deformations and chromosomal abnormalities (Q00-Q99); external causes of morbidity (V00-Y99), and factors influencing health status and contact with health services (Z00-Z99).

NOTES: Numbers may not add to totals because of rounding. Visit estimates are not presented if they are based on fewer than 30 cases in the sample data, in which case only an asterisk is shown. Visit estimates based on 30 cases or more include an asterisk if the relative standard error of the estimate exceeds $30 \%$. Proportion estimates are not presented if they are unreliable based on the procedure specified in "National Center for Health Statistics Data Presentation Standards for Proportions" (https://www.cdc.gov/nchs/data/series/sr_02/sr02_175.pdf), in which case only an asterisk is shown.

SOURCE: NCHS, National Hospital Ambulatory Medical Care Survey, 2017. 
Table 27. Hospital and emergency department characteristics, by emergency department visit volume: United States, 2017

\begin{tabular}{|c|c|c|c|c|}
\hline \multirow[b]{2}{*}{ Hospital and emergency department characteristic } & \multicolumn{4}{|c|}{ Emergency department annual visit volume ${ }^{1}$} \\
\hline & Total & Fewer than 20,000 & 20,000 to 50,000 & 50,000 or more \\
\hline & \multicolumn{4}{|c|}{ Percent distribution (standard error) } \\
\hline All emergency departments & $100.0 \ldots$ & $100.0 \ldots$ & $100.0 \ldots$ & $100.0 \ldots$ \\
\hline \multicolumn{5}{|l|}{ Hospital characteristic } \\
\hline \multicolumn{5}{|l|}{$\begin{array}{l}\text { Number of days per week that elective surgeries } \\
\text { are scheduled: }\end{array}$} \\
\hline $0-4$ & $13.5(3.6)$ & $24.7(7.0)$ & ${ }^{*} \ldots$ & ${ }^{*} \ldots$ \\
\hline 5 & $72.6(4.0)$ & $70.2(7.0)$ & **83.1 (5.4) & $64.2(6.9)$ \\
\hline $6-7$ & $11.1(2.1)$ & * $\ldots$ & ${ }^{*} \ldots$ & $32.8(6.8)$ \\
\hline Unknown or blank & * $\ldots$ & ${ }^{*} \ldots$ & ${ }^{*} \ldots$ & * $\ldots$ \\
\hline \multicolumn{5}{|l|}{ Has bed coordinator: } \\
\hline Yes & $57.3(5.0)$ & ${ }^{*} \ldots$ & $68.0(6.9)$ & **89.9 (3.2) \\
\hline No & $35.8(5.1)$ & ${ }^{*} \ldots$ & $23.0(6.1)$ & * $\ldots$ \\
\hline Unknown or black & * $\ldots$ & ${ }^{*} \ldots$ & ${ }^{*} \ldots$ & * $\ldots$ \\
\hline \multicolumn{5}{|l|}{ How often hospital bed census data are available: } \\
\hline Instantaneously & $76.8(4.6)$ & ${ }^{*} \ldots$ & **84.3 (5.4) & ${ }^{* *} 94.1(2.3)$ \\
\hline Every 4 hours & ${ }^{*} \ldots$ & ${ }^{*} \ldots$ & ${ }^{*} \ldots$ & ${ }^{*} \ldots$ \\
\hline Every 8 hours & ${ }^{*} \ldots$ & ${ }^{*} \ldots$ & ${ }^{*} \ldots$ & ${ }^{*} \ldots$ \\
\hline Every 12 hours & ${ }^{*} \ldots$ & ${ }^{*} \ldots$ & ${ }^{*} \ldots$ & ${ }^{*} \ldots$ \\
\hline Every 24 hours & $10.2(2.8)$ & $18.5(5.6)$ & ${ }^{*} \ldots$ & ${ }^{*} \ldots$ \\
\hline Unknown or blank & ${ }^{*} \ldots$ & ${ }^{*} \ldots$ & ${ }^{*} \ldots$ & ${ }^{*} \ldots$ \\
\hline \multicolumn{5}{|l|}{ Has hospitalists on staff: } \\
\hline Yes & **84.8 (5.0) & ${ }^{*} \ldots$ & **91.0 (4.5) & **98.0 (1.2) \\
\hline No & ${ }^{*} \ldots$ & ${ }^{*} \ldots$ & ${ }^{*} \ldots$ & ${ }^{*} \ldots$ \\
\hline Unknown or blank & ${ }^{*} \ldots$ & ${ }^{*} \ldots$ & ${ }^{*} \ldots$ & ${ }^{*} \ldots$ \\
\hline \multicolumn{5}{|l|}{ Has emergency medicine residency program: } \\
\hline Yes & $19.9(3.1)$ & ${ }^{*} \ldots$ & ${ }^{*} \ldots$ & $41.0(7.1)$ \\
\hline No & $73.1(3.6)$ & ${ }^{* * 92.0(3.6)}$ & ${ }^{*} \ldots$ & ${ }^{*} \ldots$ \\
\hline Unknown or blank & ${ }^{*} \ldots$ & ${ }^{*} \ldots$ & ${ }^{*} \ldots$ & ${ }^{*} \ldots$ \\
\hline \multicolumn{5}{|l|}{ Emergency department (ED) characteristic } \\
\hline \multicolumn{5}{|l|}{ ED submits claims electronically: } \\
\hline Yes & **94.2(2.0) & ${ }^{* *} 94.1(3.3)$ & **92.2 (3.6) & **97.2 (1.9) \\
\hline No & ${ }^{*} \ldots$ & ${ }^{*} \ldots$ & ${ }^{*} \ldots$ & * $\ldots$ \\
\hline Unknown or blank, or refused to answer & ${ }^{*} \ldots$ & ${ }^{*} \ldots$ & ${ }^{*} \ldots$ & ${ }^{*} \ldots$ \\
\hline \multicolumn{5}{|l|}{$\begin{array}{l}\text { ED uses electronic medical records or } \\
\text { health records: }\end{array}$} \\
\hline Yes, all electronic & $90.1(2.8)$ & **94.4 (3.6) & **85.0 (6.1) & **86.6 (4.2) \\
\hline Yes, part paper and part electronic & $8.0(2.4)$ & ${ }^{*} \ldots$ & ${ }^{*} \ldots$ & ${ }^{*} \ldots$ \\
\hline No & ${ }^{*} \ldots$ & ${ }^{*} \ldots$ & ${ }^{*} \ldots$ & ${ }^{*} \ldots$ \\
\hline Unknown or blank, or refused to answer & * $\ldots$ & ${ }^{*} \ldots$ & ${ }^{*} \ldots$ & * $\ldots$ \\
\hline \multicolumn{5}{|l|}{$\begin{array}{l}\text { ED has physically separate observation or } \\
\text { clinical decision unit: }\end{array}$} \\
\hline Yes & $39.0(4.1)$ & $29.8(6.6)$ & ${ }^{*} \ldots$ & $46.8(6.9)$ \\
\hline No & $51.7(4.7)$ & * $\ldots$ & $37.1(6.4)$ & ${ }^{*} \ldots$ \\
\hline Unknown & $9.4(2.8)$ & ${ }^{*} \ldots$ & * $\ldots$ & ${ }^{*} \ldots$ \\
\hline \multicolumn{5}{|l|}{$\begin{array}{l}\text { Admitted patients were ever boarded } 2 \text { hours or more in } \\
\text { ED or observation unit while waiting for inpatient bed: }\end{array}$} \\
\hline Yes & $56.9(4.4)$ & * $\ldots$ & $64.3(7.0)$ & $82.9(5.1)$ \\
\hline No & $36.5(4.8)$ & * $\ldots$ & $26.2(6.9)$ & * $\ldots$ \\
\hline Unknown or blank & $6.6(1.9)$ & ${ }^{*} \ldots$ & * $\ldots$ & * $\ldots$ \\
\hline
\end{tabular}


Table 27. Hospital and emergency department characteristics, by emergency department visit volume: United States, 2017-Con.

\begin{tabular}{|c|c|c|c|c|}
\hline \multirow[b]{2}{*}{ Hospital and emergency department characteristic } & \multicolumn{4}{|c|}{ Emergency department annual visit volume ${ }^{1}$} \\
\hline & Total & Fewer than 20,000 & 20,000 to 50,000 & 50,000 or more \\
\hline Emergency department (ED) characteristic-Con. & \multicolumn{4}{|c|}{ Percent distribution (standard error) } \\
\hline \multicolumn{5}{|l|}{ ED went on ambulance diversion in 2016: } \\
\hline Yes & $31.1(5.2)$ & ${ }^{*} \ldots$ & ${ }^{*} \ldots$ & $44.3(7.1)$ \\
\hline No & $57.2(5.4)$ & ${ }^{*} \ldots$ & $37.7(6.9)$ & ${ }^{*} \ldots$ \\
\hline Unknown or blank & $11.7(3.2)$ & ${ }^{*} \ldots$ & * $\ldots$ & ${ }^{*} \ldots$ \\
\hline \multicolumn{5}{|l|}{$\begin{array}{l}\text { Ambulance diversion actively managed on regional level } \\
\text { compared with each hospital adopting diversion if and } \\
\text { when it chooses }{ }^{2} \text { : }\end{array}$} \\
\hline Yes & ${ }^{*} \ldots$ & ${ }^{*} \ldots$ & ${ }^{*} \ldots$ & ${ }^{*} \ldots$ \\
\hline No & ${ }^{*} \ldots$ & ${ }^{*} \ldots$ & ${ }^{*} \ldots$ & ${ }^{*} \ldots$ \\
\hline Unknown or blank & * $\ldots$ & ${ }^{*} \ldots$ & ${ }^{*} \ldots$ & ${ }^{*} \ldots$ \\
\hline \multicolumn{5}{|l|}{$\begin{array}{l}\text { Hospital continues to admit elective or scheduled surgery } \\
\text { cases when ED is on ambulance diversion }{ }^{2} \text { : }\end{array}$} \\
\hline Yes & $* \star 81.1(6.2)$ & * ... & * $\ldots$ & * $\ldots$ \\
\hline No & * $\ldots$ & * ... & * $\ldots$ & * $\ldots$ \\
\hline Unknown or blank & * $\ldots$ & * $\ldots$ & * $\ldots$ & ${ }^{*} \ldots$ \\
\hline \multicolumn{5}{|l|}{$\begin{array}{l}\text { ED increased number of standard treatment spaces in } \\
\text { last } 2 \text { years: }\end{array}$} \\
\hline Yes & $18.2(3.4)$ & ${ }^{*} \ldots$ & ${ }^{*} \ldots$ & $32.2(6.9)$ \\
\hline No & $71.7(4.1)$ & **82.1 (5.6) & ${ }^{*} \ldots$ & * $\ldots$ \\
\hline Unknown or blank & $10.1(2.7)$ & ${ }^{*} \ldots$ & ${ }^{*} \ldots$ & ${ }^{*} \ldots$ \\
\hline \multicolumn{5}{|l|}{ ED physical space was expandedin last 2 years: } \\
\hline Yes & $12.0(2.7)$ & * $\ldots$ & * $\ldots$ & $22.5(5.6)$ \\
\hline No & $81.5(3.1)$ & **93.2 (2.8) & * $\ldots$ & $70.0(6.5)$ \\
\hline Unknown or blank & * $\ldots$ & ${ }^{*} \ldots$ & ${ }^{*} \ldots$ & * $\ldots$ \\
\hline \multicolumn{5}{|l|}{ ED plans to expand physical space in next 2 years $^{3}$ : } \\
\hline Yes & $16.9(3.2)$ & * $\ldots$ & $21.4(6.1)$ & * $\ldots$ \\
\hline No & $67.5(4.8)$ & $* * 81.4(6.7)$ & * $\ldots$ & ${ }^{*} \ldots$ \\
\hline Unknown or blank & $15.6(3.5)$ & ${ }^{*} \ldots$ & ${ }^{*} \ldots$ & ${ }^{*} \ldots$ \\
\hline \multicolumn{5}{|l|}{ Services ED uses: } \\
\hline Bedside registration & $79.4(3.9)$ & $73.1(6.4)$ & $79.9(7.1)$ & **94.1 (3.1) \\
\hline Kiosk self check-in & * $\ldots$ & * $\ldots$ & * $\ldots$ & * $\ldots$ \\
\hline Computer-assisted triage & $47.6(6.0)$ & ${ }^{*} \ldots$ & * $\ldots$ & $66.2(6.4)$ \\
\hline Immediate bedding & $71.7(4.5)$ & $73.5(6.5)$ & * & $71.5(5.7)$ \\
\hline Advanced triage (triage-based care) protocols & $70.7(5.0)$ & ${ }^{*} \ldots$ & $74.3(6.9)$ & $81.1(5.2)$ \\
\hline Physician or practitioner at triage & $38.6(4.4)$ & $27.5(5.9)$ & ${ }^{*} \ldots$ & ${ }^{*} \ldots$ \\
\hline Separate fast-track unit for nonurgent care & $47.7(5.9)$ & ${ }^{*} \ldots$ & ${ }^{*} \ldots$ & $78.5(5.9)$ \\
\hline Separate operating room dedicated to ED patients & $9.0(2.5)$ & ${ }^{*} \ldots$ & ${ }^{*} \ldots$ & ${ }^{*} \ldots$ \\
\hline Electronic dashboard ${ }^{4}$ & $77.7(4.8)$ & * $\ldots$ & **86.7 (5.0) & **85.5 (5.0) \\
\hline Radio frequency identification tracking ${ }^{5}$ & $21.0(5.3)$ & * $\ldots$ & * $\ldots$ & $15.0(4.4)$ \\
\hline Wireless devices by providers & $57.0(4.8)$ & ${ }^{*} \ldots$ & ${ }^{*} \ldots$ & $76.8(4.6)$ \\
\hline Zone nursing ${ }^{6}$ & $57.5(4.7)$ & $39.7(6.5)$ & $76.2(6.1)$ & $74.8(6.3)$ \\
\hline Pool nurses ${ }^{7}$ & $56.1(4.7)$ & $51.6(6.8)$ & * $\ldots$ & * $\ldots$ \\
\hline
\end{tabular}

... Category not applicable.

* Estimate does not meet NCHS standards of reliability.

** Estimate meets NCHS standards of reliability, but its complement does not.

${ }^{1}$ Number of hospitals for all emergency departments (EDs) $(N=199)$; Fewer than 20,000 ( $\left.N=62\right) ; 20,000-49,999(N=59)$; and 50,000 or more $(N=78)$.

${ }^{2}$ Denominator is number of EDs on ambulance diversion or for which ambulance diversion status is unknown.

${ }^{3}$ Denominator is number of EDs that did not expand physical space in the last 2 years, including unknown or blank responses.

${ }^{4}$ Displays updated patient information and integrates multiple data sources.

${ }^{5}$ Shows exact location of patients, caregivers, and equipmen

${ }^{6}$ Refers to all of a nurse's patients being located in one area.

${ }^{7}$ Nurses who can be pulled into the ED on demand to respond to surges.

NOTES: Estimates are not presented if they are based on fewer than 30 cases in the sample data, in which case only an asterisk is shown. Estimates based on 30 cases or more include an asterisk if the relative standard error of the estimate exceeds $30 \%$. Proportion estimates are not presented if they are unreliable based on the procedure specified in "National Center for Health Statistics Data Presentation Standards for Proportions" (https://www.cdc.gov/nchs/data/series/sr_02/sr02_175.pdf), in which case only an asterisk is shown.

SOURCE: NCHS, National Hospital Ambulatory Medical Care Survey, 2017. 